\title{
Clinical Probes and Endogenous Biomarkers as Substrates for Transporter Drug-Drug Interaction Evaluation: Perspectives From the International Transporter Consortium
}

DOI:

10.1002/cpt.1216

Document Version

Accepted author manuscript

Link to publication record in Manchester Research Explorer

Citation for published version (APA):

Chu, X., Liao, M., Shen, H., Yoshida, K., Zur, A. A., Arya, V., Galetin, A., Giacomini, K. M., Hanna, I., Kusuhara, H., Lai, Y., Rodrigues, D., Sugiyama, Y., Zamek-gliszczynski, M. J., \& Zhang, L. (2018). Clinical Probes and Endogenous Biomarkers as Substrates for Transporter Drug-Drug Interaction Evaluation: Perspectives From the International Transporter Consortium. Clinical Pharmacology \& Therapeutics, 104(5), 836-864.

https://doi.org/10.1002/cpt.1216

Published in:

Clinical Pharmacology \& Therapeutics

\section{Citing this paper}

Please note that where the full-text provided on Manchester Research Explorer is the Author Accepted Manuscript or Proof version this may differ from the final Published version. If citing, it is advised that you check and use the publisher's definitive version.

\section{General rights}

Copyright and moral rights for the publications made accessible in the Research Explorer are retained by the authors and/or other copyright owners and it is a condition of accessing publications that users recognise and abide by the legal requirements associated with these rights.

\section{Takedown policy}

If you believe that this document breaches copyright please refer to the University of Manchester's Takedown Procedures [http://man.ac.uk/04Y6Bo] or contact uml.scholarlycommunications@manchester.ac.uk providing relevant details, so we can investigate your claim. 


\section{Clinical Probes and Endogenous Biomarkers as Substrates for Transporter DDI}

\section{Evaluation: Perspectives from the International Transporter Consortium}

3

Xiaoyan $\mathrm{Chu}^{1}{ }^{*}$, Mingxiang Liao ${ }^{2}$, Hong Shen ${ }^{3}$, Kenta Yoshida ${ }^{4}$, Arik A. Zur ${ }^{5}$, Vikram Arya ${ }^{6}$, Aleksandra Galetin ${ }^{7}$, Kathleen M. Giacomini ${ }^{8}$, Imad Hanna ${ }^{9}$, Hiroyuki Kusuhara ${ }^{10}$, Yurong Lai ${ }^{11}$, A. David Rodrigues ${ }^{12}$, Yuichi Sugiyama ${ }^{13}$, Maciej J. Zamek-Gliszczynski ${ }^{14}$, and Lei Zhang ${ }^{15}$ * on behalf of the International Transporter Consortium

1. Department of Pharmacokinetics, Pharmacodynamics and Drug Metabolism, Merck \& Co., Inc, Kenilworth, New Jersey, USA;

2. Department of Clinical Pharmacology, Clovis Oncology, Inc., Boulder, Colorado, USA;

3. Department of Metabolism and Pharmacokinetics, Bristol-Myers Squibb, Princeton, New Jersey, USA;

4. Clinical Pharmacology, Genentech Research and Early Development, South San Francisco, California, USA;

5. BiolineRX, Modi'in, Israel;

6. Division of Clinical Pharmacology IV, Office of Clinical Pharmacology, Office of Translational Sciences, Center for Drug Evaluation and Research, Food and Drug Administration, Silver Spring, Maryland, USA;

7. Centre for Applied Pharmacokinetic Research, School of Health Sciences, University of Manchester, UK;

8. Department of Bioengineering and Therapeutic Sciences, Schools of Pharmacy and Medicine, University of California, San Francisco, California, USA;

9. Pharmacokinetics Sciences, Novartis Institutes for Biomedical Research, East Hanover, New Jersey, USA;

10. Graduate School of Pharmaceutical Sciences, the University of Tokyo, Tokyo, Japan;

11. Departments of Clinical Research, Clinical Pharmacology, and Drug Metabolism and Pharmacokinetics, Gilead Science, Inc., Foster City, California, USA;

12. Pharmacokinetics, Dynamics, \& Metabolism, Medicine Design, Pfizer Inc, Groton, Connecticut, USA;

13. Sugiyama Laboratory, RIKEN Innovation Center, Research Cluster for Innovation, RIKEN, Yokohama, Japan;

14. Quantitative Drug Disposition, GlaxoSmithKline plc, 709 Swedeland Road, King of Prussia, Pennsylvania, USA;

15. Office of Research and Standards, Office of Generic Drugs, Center for Drug Evaluation and Research, Food and Drug Administration, Silver Spring, Maryland, USA. 


\section{$37 *$ Corresponding authors}

38 Xiaoyan Chu, Ph.D.

39 RYN800-B210

40126 East Lincoln Ave

41 Merck \& Co., Inc

42 Rahway, NJ 07065, USA

43 Tel: 732-594-0977

44 E-mail: xiaoyan chu@merck.com

45

46 Lei Zhang, Ph.D.

4710903 New Hampshire Ave.

48 Silver Spring, MD 20993, USA

49 Tel. 301-796-1635

50 Email: leik.zhang@fda.hhs.gov

51

52

Abstract: $150 / 150$ words

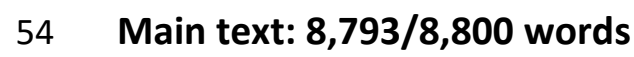

55 Number of References: 110/110

56 Number of Figures/Tables: 8/8

57 Number of Supplementary Figures/Tables: $\mathbf{5}$

58

61 The authors declared no competing interests for this work.

62

\section{FUNDING}

64

65 No funding was received for this work.

\section{Abbreviation List:}

67 ADME, Absorption, distribution, metabolism, and excretion; AUC, area under the concentration68 time curve; AUCR, ratio of AUC; BCRP, breast cancer resistance protein; $6 \beta H C, 6 \beta-$ 69 hydroxycortisol; CL, clearance; CYP, cytochrome P450; CB, conjugated bilirubin; CP, 70 coproporphyrin; $C_{\max }$, maximum concentration; $C_{\max } R$, ratio of $C_{\max } ; C_{r}$, renal clearance; $C L_{r} R$, 
71 ratio of $\mathrm{CL}_{r}$; $\mathrm{DDI}$, drug-drug interaction; $\mathrm{DE}$, dabigatran etexilate; GCDCA-S, 72 glycochenodeoxycholate-3-O-sulfate; GWAS, genome wide association study; HDA, 73 hexadecanedioate; IVIVE, in vitro to in vivo extrapolation; ITC, International Transporter 74 Consortium; $I C_{50}$, half maximal inhibitory concentration; $K_{m}$, Michaelis constant; $K_{i}$, inhibition 75 rate constant; MDR, multidrug resistance; MRP, multidrug resistance protein; MATE, multidrug 76 and toxin extrusion protein; NME, new molecular entity; NMN, N1-methylnicotinamide; NTCP, 77 sodium taurocholate co-transporting polypeptide; OATP, organic anion transporting polypeptide; 78 OAT, organic anion transporter; OCT, organic cation transporter; P-gp, P-glycoprotein; PBPK, 79 physiologically-based pharmacokinetic; PK, pharmacokinetics; PPB, plasma protein binding; $\mathrm{t}_{1 / 2}$, 80 half-life; THTR, thiamine transporter; TDA, tetradecanedioate; UCB, unconjugated bilirubin. 


\section{Abstract (150/150)}

Drug transporters can govern the absorption, distribution, metabolism, and excretion of

85 substrate drugs and endogenous substances. Investigations to examine their potential impact to

86 pharmacokinetic drug-drug interactions (DDIs) are an integral part of the risk assessment in drug

87 development. To evaluate a new molecular entity as a potential perpetrator of transporters, use

88 of well characterized and/or clinically relevant probe substrates with good selectivity and 89 sensitivity are critical for robust clinical DDI assessment that could inform DDI management

90 strategy in the product labeling. The availability of endogenous biomarkers to monitor

91 transporter-mediated DDIs in early phases of clinical investigations would greatly benefit

92 downstream clinical plans. This article reviews the state-of-the-art in transporter clinical probe

93 drugs and emerging biomarkers including current challenges and limitations, delineates methods

94 and workflows to identify and validate novel endogenous biomarkers to support clinical DDI

95 evaluations, and proposes how these probe drugs or biomarkers could be used in drug 96 development. 
Drug transporters can modulate the absorption, distribution, metabolism, and excretion (ADME) of substrate drugs and endogenous substances, ultimately determining their exposure in systemic circulation and tissues. ${ }^{1}$ Transporter substrate or modulator (inhibitor or inducer) drugs can become clinical victims or perpetrators of DDIs, respectively, when the transporter in question is a substantial contributor to the pharmacokinetics (PK) of the victim drug and can be inhibited or induced in the clinical setting. For example, lapatinib, a P-glycoprotein (P-gp) inhibitor, increased digoxin exposure by 2.8-fold (TYKERB labeling at Drugs@FDA), whereas tipranavir/ritonavir, a P-gp inducer, decreased saquinavir/ritonavir exposure by 76\% (APTIVUS labeling at Drugs@FDA). Understanding DDIs is an integral part of risk assessment in drug development considering the common practice of concomitant use of multiple medications. ${ }^{1-3}$

Previous International Transporter Consortium (ITC) whitepapers and regulatory guidelines have proposed an integrated approach (in vitro, in vivo, in silico) to assess DDI potential and to inform safe drug use. ${ }^{1-10}$ Multiple factors contribute to the decision whether a clinical DDI study may be necessary, and if so, its prioritization during drug development, and subsequent interpretation of clinical DDI data to inform the product labeling. From the perspective of a new molecular entity (NME) as a transporter inhibitor, prediction of clinical DDI potential involves comparison of in vitro transporter inhibitory potency to various transporters that govern the victim drug's intestinal, liver portal, systemic and tissue exposure. In this regard, in vitro transporter inhibition assays have been routinely used to determine whether an NME is an inhibitor of clinically-relevant transporters, which serve as a trigger for follow up clinical DDI studies. ${ }^{9,10}$ However, this approach may result in false positive or false negative predictions due to the limitations of in vitro transporter assays and/or gaps in in vitro to in vivo extrapolation (IVIVE). ${ }^{711}$ For instance, the assumptions are often made that the transportermediated pathway accounts for $100 \%$ of drug elimination, however, the contribution of transporter(s) to overall elimination of drugs is often not known or cannot be accurately measured.

Endogenous substances can exhibit transporter-mediated disposition, and their concentrations may be altered when transporter activity is modulated. ${ }^{12,13,14}$ These 
endogenous substances have the potential to serve as biomarkers to study transporter function in vivo in humans. Transporter biomarkers offer the potential for evaluating NMEs as transporter inhibitors in early clinical studies, and with appropriate validation, may obviate the need for dedicated clinical DDI studies. For the purposes of drug development planning, it would be invaluable to corroborate or refute inhibition of transporters predicted from in vitro data using biomarkers, particularly in situations where in vitro prediction methods have high false positive rates. For clinical DDI studies evaluating an NME as an inhibitor, use of selective and sensitive probe substrate drugs is a key to determine clinical risk for transporter inhibition, provide a mechanistic insight, extrapolate the results to other unstudied drugs, and inform the drug labeling to provide recommendations based on the DDI results. However, this has been challenging by the multiplicity of transporter substrates and inhibitors, the presence of multiple drug binding sites in many drug transporters, and complex interplay with drug metabolizing enzymes $^{4-6,10}$. Therefore, probe drugs currently used for clinical DDI studies are largely based on the likelihood of co-administration, without comprehensive understanding and evaluation of their ADME properties/in vitro transporter profiles, which limits extrapolation of the results to other drugs. Validated clinical probes are critical for robust clinical DDI assessment that ultimately drives product labeling to inform concomitant drug use. Table 1 outlines key features of an ideal probe drug or a biomarker which can be used in vivo to assess transporter perpetrator DDIs. Notably, very few such probe substrate drugs or biomarkers have been identified to date.

This article reviews the state-of-the-art of transporter clinical probe drugs and emerging biomarkers, provides recommendations on use of relevant transporter probe substrates for DDI evaluation, and some potential transporter endogenous biomarkers for further characterization and validation, as well as current challenges and limitations. Furthermore, the article practically delineates methods and workflows to identify and validate novel endogenous biomarkers to support clinical DDI evaluation, and proposes their potential utility and application in drug development. 
STATE-OF-THE ART IN CLINICAL PROBE DRUGS AND POTENTIAL ENDOGENOUS BIOMARKERS FOR CLINICAL TRANSPORTER DDI ASSESSMENT

Clinical DDI assessment for an NME as a transporter inhibitor is typically conducted by administering an accepted probe substrate with the NME. In this section, we have conducted a critical and comprehensive analysis of probe substrate drugs commonly used for the transporters recommended by the ITC and regulatory agencies for clinical DDI evaluation based on their ADME properties, in vitro transporter profiles, and in vitro and clinical DDI data . 1, 4-6, 9, 10

Figure 1 illustrates recommended probe substrate drugs with a relatively high selectivity (based on relative contribution of transporter-mediated pathways to overall elimination of drugs) and sensitivity (based on clinical DDI studies with known potent transporter inhibitors and/or pharmacogenomic studies in subjects carrying non- or reduced-function alleles) ${ }^{15,16}$ with detailed ADME properties, in vitro transporter profile, and examples of clinical DDIs summarized in Table 2 . These probe substrate drugs in general meet the following criteria:

- In vitro transporter profiles are relatively well characterized, and show higher transport activity and selectivity for the transporter of interest

- Clinical data show significant contribution of the transporter of interest in the overall elimination as indicated by

0 the ratio of area under the plasma concentration-time profile $(A \cup C R) \geq 2$

0 and/or the ratio of plasma clearance $(C L)$ (or renal clearance $\left(C_{r}\right)$ for renal transporters) $\mathrm{CLR}$ or $\mathrm{CL}_{r} \mathrm{R} \leq 0.5$

Either in the presence of a potent transporter inhibitor or in subjects with reduced function caused by a transporter polymorphism

- Are commercially available and have relatively rich clinical DDI data 
In this section, potential utility and limitations of probe substrate drugs summarized in

180 Figure 1 are discussed, together with recent examples of clinical probe drug cocktails used to 181 simultaneously explore DDIs involving multiple drug transporters and metabolizing enzymes. ${ }^{17-}$ $182 \quad 20$

Several endogenous substrates have been identified as potential endogenous biomarkers to evaluate inhibition of several hepatic and renal transporters in humans. ${ }^{12,13,14}$ The endogenous substrates with initial clinical DDI evaluation are highlighted in Figure 1.

186 Recent progress in identifying and evaluating these potential biomarkers are discussed below and some key preclinical and clinical data are summarized in Table $\mathbf{3}$ and Table $\mathbf{S 1 .}$ Cation Transporter 1 (OCT1)

Pitavastatin, rosuvastatin, and atorvastatin are widely used as clinical probe drugs for the evaluation of OATP1B-mediated DDIs, either following a clinically-relevant oral dose or a

195 microdose as part of a drug cocktail ${ }^{18,21,22}$ (Figure 1, Table 2). Although considered as OATP1B 196 substrates, the aforementioned drugs as well as other proposed "probes" have been shown to 197 be substrates for other transporters in vitro, such as OATP2B1, sodium-taurocholate co198 transporting polypeptide (NTCP), breast cancer resistance protein (BCRP), P-glycoprotein (P-gp), 199 organic anion transporter 3 (OAT3), and multidrug resistance-associated protein 4 (MRP4) and 200 MRP3. ${ }^{21,23,24}$

Pitavastatin is considered as the most sensitive OATP1B1 probe, ${ }^{22}$ supported by $>80 \%$

202 fraction transported via OATP1B1, which has been estimated from in vitro, human ADME, 203 SLCO1B1 (OATP1B1) c. 521T>C pharmacogenomic data and DDI data with intravenous (i.v.) vs. 
orally-administered rifampin, a potent inhibitor for OATP1B. Pharmacogenomic data highlight similar sensitivity to SCLO1B1 for simvastatin acid, ${ }^{15,16,25}$ but its complex PK (lactone-acid interconversion) and OATP1B-CYP3A interplay may limit its general use as a selective OATP1B clinical probe. In the case of rosuvastatin, the alteration of the activity of multiple non-OATP1B transporters expressed either in the intestine (BCRP and OATP2B1), liver (NTCP and OATP2B1), or kidney (OAT3) may be the driver behind the observed change in its PK following the oral administration of an inhibitor that can affect these transporters. Like rosuvastatin, atorvastatin presents a suitable OATP1B1 probe drug because of supporting pharmacogenomics data, ${ }^{26}$ clinical DDI data with rifampin and mechanistic insight regarding OATP1B as the ratedetermining step driving its hepatic disposition. ${ }^{27}$ Nonetheless, the potential effect of inhibiting intestinal CYP3A4 and BCRP/P-gp efflux should also be considered when interpreting the observed changes in its systemic exposure.

\section{- Endogenous Substrates (Potential Biomarker)}

To date, the endogenous substrates of OATP1B include coproporphyrins (CPs), bile acids (BAs), sulfated and glucuronidated BAs, fatty acid dicarboxylates, bilirubin, glucuronidated bilirubin, thyroid hormones and their metabolites, steroids, and sulfated and glucuronidated steroids. Among them CPI, CPIII, glycochenodeoxycholate-3-O-sulfate (GCDCA-S), hexadecanedioate (HDA), tetradecanedioate (TDA), conjugated and unconjugated bilirubin (CB and UCB) present as potential biomarkers for clinical evaluation of OATP1B-mediated DDIs, but each has limitations ${ }^{12,13}{ }^{14}$ (Figure 1, Table 3). In most cases, evidence for their utility as OATP1B biomarkers is based on animal data and careful profiling of plasma and urine of human SLCO1B genotyped subjects. For example, patients with Rotor's syndrome lack expression of OATP1B1 and OATP1B3 are characterized by increased urinary excretion of CPI and higher bilirubin in the blood due to reduced secretion into the bile. ${ }^{28}$ Likewise, pharmacogenomic studies indicate that individuals genotyped SLCO1B1*15 and C.521T>C show increased exposure of UCB, CB and some BAs. ${ }^{29-31}$ Compelling clinical evidence supporting HDA, TDA, GCDCA-S and bilirubin as potential endogenous biomarkers for OATP1B1 has come from metabolomic and genome-wide association studies (GWAS), which show a significant association of SLCO1B1 
521T $>C$ with the plasma levels of these endogenous substances..$^{32-34}$ The clinical data are consistent with the results obtained in Oatp $1 a / 1 b^{-/}$mice, as they exhibit higher plasma CPI, CPIII, UCB, CB and BA concentrations ${ }^{28,35,36}$ (Table S1). In addition, in vitro studies using transporter-transfected cells and hepatocytes with an OATP1B inhibitor (e.g., rifampin) confirm that CPI, CPIII, GCDCA-S, HDA, TDA, CB and UCB are substrates for OATP1B1 (Table 3). These biomarkers are also substrates for OATP1B3 with the exception of HDA and TDA. In addition, they are also transported by other hepatic and renal transporters such as MRP2 and MRP3 (CPI, CPIII and CB), OATP2B1 (CPIII), OAT1 (HDA and TDA), OAT3 (GCDCA-S, HDA, and TDA), and NTCP (GCDCA-S) (Table 3), which may limit their selectivity.

Concerns regarding transporter selectivity aside, the above mentioned endogenous biomarkers are capable of recapitulating some clinical OATP1B DDIs. For example, a single oral dose of rifampin $(600 \mathrm{mg}$ ) has been shown to markedly increased the AUC of GCDCA-S (10-20fold). ${ }^{41}$ This increase was significantly greater than the changes in plasma simeprevir, bosentan, and repaglinide exposures in the same study (7.2-, 3.2- and 1.9-fold, respectively). ${ }^{34}$ Results of recent studies have also shown that changes in CPI plasma exposure correlate with presumably different levels of OATP1B inhibition imposed by OATP1B inhibitors that showed different in vivo inhibition (e.g., simeprevir, JNJ-A, and GDC-0810) with known OATP1B substrates. ${ }^{37}$ To date, however, reported OATP1B clinical DDI studies with concomitant monitoring of both clinical probe drugs and endogenous biomarker(s) are still limited in number. ${ }^{38-41}$ (Table 3).

In summary, CPI, CPIII, GCDCA-S, HDA, TDA, CB and UCB have demonstrated initial promise as clinical OATP1B biomarkers, in which, CPI appears to be the most promising biomarker with higher selectivity and sensitivity. Further characterization and validation is needed to determine their predictive value for OATP1B-related DDIs. Until other confounding factors, including overlapping substrate selectivity for transporters and enzymes, disease, diet, and circadian rhythm, are fully understood, a single OATP1B biomarker may not be sufficient for effective overall evaluation of OATP1B inhibition risk and the use of multiple biomarkers may be warranted. 
Metformin is a well-known substrate of OCT1. It is also a substrate for OCT2 and multidrug and toxin extrusion protein MATE1 and MATE2K. Metformin may not be a suitable clinical OCT1 probe drug if only changes in PK is monitored, ${ }^{42}$ because OCT1 modulation does not impact metformin systemic PK, and it only impacts metformin hepatic distribution and pharmacodynamics (PD) response. ${ }^{42,43}$ Currently, OCT1 probe substrate drugs have only been validated clinically in pharmacogenetic studies by comparing individuals expressing inactive or reduced function of OCT1 vs. wildtype controls. ${ }^{15,42,44}$ Clinical OCT1 probes identified to date include sumatriptan, ${ }^{45}$ ondansetron, and tropisetron. ${ }^{46}$ Overall, sumatriptan and tropisetron are promising probe substrates of OCT1 because they exhibit a 2.2 -fold and 4.9 -fold increase in AUC, respectively, in subjects with a polymorphism resulting in reduced OCT1 activity vs. controls. $^{45,46}$ Of the two, sumatriptan is most promising as a drug probe for OCT1 because evidence is available from a prospective study in healthy subjects ${ }^{45}$ (Table 2). Additional DDI studies with OCT1 inhibitors are warranted to better characterize their clinical utility as probe drugs for OCT1.

Fenoterol is also a promising clinical OCT1 probe with both notable systemic PK and PD 277 effects of OCT1 modulation, but it is practically problematic, because it is not approved in the US. ${ }^{47}$ The O-desmethyl metabolite of tramadol ${ }^{48,49}$ is a sensitive OCT1 probe with both notable PK and PD effects during OCT1 modulation. However, metabolites are generally not preferred 280 probes in the drug development setting due to additional data interpretation complexity

282 (e.g., pharmacogenetic factors). Morphine ${ }^{50}$ may be a useful OCT1 probe, but clinical studies conducted to-date were inconsistent, and morphine cannot presently be recommended as an OCT1 probe until these findings are clarified (e.g., oral administration of the prodrug versus parenteral administration of morphine directly). Besides OCT1, morphine is a substrate for 287 substances are not practical (or safe). 
Thiamine is a substrate of OCT1 ${ }^{51}$ (Table S1), however, clinical evidence supporting thiamine as an endogenous OCT1 probe is lacking. Preclinical studies using Oct1 ${ }^{-}$mice showed that the concentrations of thiamine and its metabolites in the knockout mouse liver following i.v. administration were reduced by more than $50 \%$ compared to wild-type animals, whereas plasma levels were increased $30-40 \%$, confirming the role of Oct1 in thiamine hepatic disposition in vivo. However, thiamine is not selective for OCT1 because it is also a substrate for OCT2, MATE1, MATE2K, thiamine transporter 1 and 2 (THTR1 and THTR2). ${ }^{52,53}$ Notably, up to $9 \%$ of Caucasians exhibit an OCT1 deficient phenotype, which has not been associated with markedly elevated systemic thiamine concentrations possibly due to variability associated with dietary intake. This may make thiamine an impractical clinical OCT1 biomarker.

Recently, acylcarnitines, intermediate metabolites of mitochondrial oxidation, was identified as endogenous substrates of OCT1 through GWAS, targeted metabolomics, transporter transfected cells, and Oct1 liver specific knockout mice. ${ }^{54}$ These studies have

302 illustrated the role of OCT1 in the efflux of acylcarnitines from the liver to the circulation. Additional clinical DDI studies, however, are needed to assess the suitability of acylcarnitine as a potential endogenous biomarker of OCT1. It is worth noting that the GWAS showed that serum acylcarnitine levels are also significantly associated with organic cation/carnitine 306 transporter 1 (OCTN1; SLC22A4), UGT1A1 and carnitine palmitoyltransferase 1 (CPT1) genes ${ }^{55}$ and acylcarnitine is also an in vitro substrate of OCTN2, which may limit the selectivity of acylcarnitine as a biomarker for OCT1..$^{55}$

OAT1/3 
Despite overlapping substrate selectivity between OAT1 and OAT3, adefovir is a relatively selective OAT1 probe, because its transport by OAT3 is minimal ${ }^{56}$ (Figure 1, Table 2). Adefovir is also transported by the apically localized renal efflux transporter MRP4. ${ }^{57}$ However, plasma and renal clearance of adefovir was only slightly decreased in $\mathrm{Mrp4}^{-/}$mice, suggesting that change in Mrp4 activity may not have significant impact on its plasma exposure. ${ }^{57}$ Probenecid, a potent inhibitor of OATs, caused a 2.1-fold increase in adefovir plasma AUC (Table 2), suggesting that adefovir may be used as a probe drug for OAT1. In contrast, benzylpenicillin (also named as Penicillin G) (Figure 1, Table 2) is a more selective OAT3 substrate compared to OAT1. ${ }^{56,58}$ Probenecid increased plasma AUC of benzylpenicillin by 3.3fold $^{56}$ (Table 2), suggesting that it may serve as an OAT3 probe substrate. As discussed in drug probe cocktail section below, furosemide, a dual substrate of OAT1 and OAT3, could be a useful probe to study the inhibition to both OAT1 and OAT3. ${ }^{17}$

\section{- Endogenous Substrates (Potential Biomarker)}

Taurine is an endogenous OAT1 substrate, whereas $6 \beta$-hydroxycortisol $(6 \beta \mathrm{HC})$ and GCDCA-S are substrates of OAT3; they may therefore potentially serve as endogenous biomarkers for assessing DDIs with these transporters ${ }^{12,13}$ (Figure 1, Table 3). In a clinical study, probenecid exhibited dose-dependent reduction of $\mathrm{CL}_{r}$ of taurine and $\mathrm{GCDCA}-\mathrm{S}$ without altering their plasma AUC. Moreover, the $\mathrm{CL}_{r}$ values for either compound correlated strongly with benzylpenicillin (an OAT3 probe drug) and 6BHC, suggesting that either compound could be a useful biomarker for OAT1 or OAT3. ${ }^{59}$ Unlike $6 \beta \mathrm{HC}$, the $\mathrm{CL}_{r}$ of taurine and $\mathrm{GCDCA}-\mathrm{S}$ was below GFR, indicating potential reabsorption from the urine in addition to tubular secretion. The selectivity of GCDCA-S as an endogenous OAT3 probe is limited since probenecid can inhibit apically-localized OAT4 and MRP2, which may be involved in the reabsorption and urinary excretion of GCDCA-S, respectively. Additionally, GCDCA-S is also known as an endogenous substrate of hepatic OATP1B ${ }^{60}$ (Table 3) and, as such, may confound its selectivity for OAT3. $6 \beta \mathrm{HC}$ is formed by hepatic CYP3A4 and excreted into urine. It is also known as a biomarker for induction of CYP3A4 and any change in CYP3A4 activity may therefore influence the sensitivity and selectivity of $6 \beta \mathrm{HC}$ as an OAT3 probe. ${ }^{61}$ Besides OAT3, $6 \beta \mathrm{HC}$ is a substrate for MATE1 and 
MATE2K. ${ }^{62}$ Probenecid significantly increased plasma $A U C$, but reduced $\mathrm{CL}_{r}$ of $6 \beta \mathrm{HC}$, whereas pyrimethamine (a MATEs inhibitor) did not change systemic $6 \beta \mathrm{HC}$ AUC or $\mathrm{CL}_{r}$ significantly. ${ }^{62}$ Neither probenecid nor pyrimethamine affected CYP3A4 and 11ß-hydroxysteroid dehydrogenase 2 activity responsible for the formation of $6 \beta \mathrm{HC}$ and conversion of $6 \beta \mathrm{HC}$ to $6 \beta$ hydroxycortisone, respectively. ${ }^{62}$ Recently, pyridoxic acid and homovanillic acid have been identified as endogenous substrates of OAT1/3 using metabolomic analysis and DDI studies in cynomolgus monkeys. ${ }^{63}$ Additional studies are needed to validate their potential utility as OAT1 $/ 3$ endogenous biomarkers in human.

\section{OCT2, MATE1/2K}

\section{- Probe Drugs}

Metformin is a well-known and broadly used probe drug to study inhibition of the renal uptake transporter OCT2, and efflux transporters MATE1/2K. ${ }^{64}$ For example, MATE1/2K inhibitor pyrimethamine significantly changed metformin plasma $\mathrm{AUC}$ and $\mathrm{CL}_{r}$ by the inhibition of active renal secretion ${ }^{65,66}$ (Figure 1, Table 2). However, distribution of metformin to the liver, its primary site of action, but not clearance, is mediated by OCT1. ${ }^{67}$ Recent studies suggest that metformin is also a substrate of OCT3, which is a key to its skeletal muscle distribution (another site of action). The absorption and distribution of metformin is a complex and poorly understood process that involves at least several transporters, including THTR-2 and OCT1/3. ${ }^{64}$ Lack of selectivity of most transporter inhibitors complicates further the interpretation of metformin renal DDI data. For instance, famotidine (a selective MATE1 inhibitor) at a high dose (200-800 $\mathrm{mg} /$ day) resulted in an increase, rather than the expected decrease in metformin $\mathrm{CL}_{\text {.. }}{ }^{68}$ Famotidine co-administration also caused a transient enhancement of the anti-hyperglycemic effects of metformin, likely due to enhanced hepatic distribution through MATE1 inhibition. ${ }^{68}$ Due to the unique complexity of metformin mechanistic disposition, a separate commentary in this issue of CPT is dedicated to clinical DDI study design consideration for metformin. ${ }^{43}$ 
N1-methylnicotinamide (NMN) is an endogenous substrate of OCT2, MATE1/ $2 \mathrm{~K} .{ }^{69}$

371 Pyrimethamine almost completely inhibited its $C_{r}$ via active secretion without altering its

372 plasma exposure. ${ }^{69}$ Trimethoprim, another OCT2/MATEs inhibitor, also reduced NMN $\mathrm{CL}_{r}$,

373 which correlated with the change in metformin exposure in the same healthy subjects. ${ }^{70}$

374 Recent studies reported increased NMN CLr in pregnant women which was positively correlated

375 with increase in metformin $\mathrm{CL}_{r}{ }^{71}$ These clinical observations suggest the potential use of NMN

376 as an endogenous probe for DDIs involving OCT2/MATEs (Figure 1, Table 3). However, it is

377 worth noting that renal elimination of NMN also involves active tubular reabsorption. ${ }^{72}$

Creatinine is commonly used as a biomarker for renal function. Increased serum

379 creatinine and reduced creatinine $C_{r}$ could be a result of transient inhibition of renal 380 transporters involved in its active secretion (OCT2, OAT2, MATE1/2K), without altering GFR ${ }^{73}$

381 (Figure 1, Table 3). However, creatinine levels are influenced by many factors such as weight, 382 gender, age, muscle metabolism, and diet. A retrospective analysis of the change of creatinine 383 level and DDI data with OCT2/MATEs inhibition suggests that creatinine is not a sensitive 384 biomarker for OCT2/MATEs inhibition, despite the fact that elevation of serum creatinine is 385 frequently associated with inhibition of OCT2/MATEs. ${ }^{73}$ Therefore, incorporation of creatinine 386 with other biomarkers, such as NMN may be needed to evaluate the risk for OCT2/MATEs 387 inhibition.

Gut Transporters: P-gp and BCRP

- Probe Drugs

Digoxin, dabigatran etexilate (DE), and fexofenadine are recommended by regulatory 393 agencies as clinical probe drugs for P-gp inhibition (Figure 1, Table 2). However, there are a 
number of limitations regarding the suitability of digoxin as a P-gp probe including the involvement of additional transporters and/or the low sensitivity of the DDI signal largely due to high oral bioavailability (60-80\%). Despite these limitations, clinical DDIs with digoxin have been most extensively evaluated because digoxin exhibits a narrow therapeutic index and is commonly used in the clinical setting. The impact of NMEs on digoxin PK should therefore be carefully monitored as a safety precaution. ${ }^{74}$ However, DDI data obtained with digoxin cannot be readily extrapolated to other P-gp substrate drugs. ${ }^{75}$ The limitation of fexofenadine as a Pgp probe is the involvement of OATPs (OATP2B1, OATP1B1/1B3) and OAT3 in its absorption, hepatic and renal elimination. ${ }^{76,77}$ Fexofenadine therefore can be selected as a P-gp probe only when OATPS /OAT3 inhibition is not involved in the DDIs. DE, a prodrug of dabigatran, is a P-gp substrate, whereas its active moiety dabigatran is not. ${ }^{78}$ Thus, DE could be a more selective P-gp probe to study P-gp inhibition in the gut, as P-gp-mediated efflux is restricted to limiting intestinal absorption of DE. However, PK variability, conversion of DE to dabigatran via carboxylesterases, and potential saturation of P-gp in the gut at therapeutic dose may impact its sensitivity and selectivity. ${ }^{79}$ Given their relatively low bioavailability (Table 2), DE and fexofenadine may be more appropriate P-gp probes in comparison to digoxin when evaluating intestinal P-gp inhibition.

- Endogenous Substrates (Potential Biomarker) To date, no endogenous probe for P-gp has been identified. ${ }^{13}$

\section{$B C R P$}

\section{- Probe Drugs}

It is challenging to identify clinical BCRP probes due to the multiplicity of substrates and inhibitors, as well as potential BCRP interactions both in the gut and liver. Following a comprehensive review of in vitro, clinical DDI, and pharmacogenomic data, sulfasalazine has been proposed as an in vivo probe for evaluating intestinal BCRP inhibition, intravenous 
421 rosuvastatin for evaluating hepatic BCRP inhibition, and oral rosuvastatin for both intestinal and

422 hepatic BCRP inhibition. ${ }^{24}$ Sulfasalazine has limited intestinal absorption due to its low

423 permeability, low solubility, and BCRP-mediated intestinal efflux (Figure 1, Table 2). Plasma

424 AUC of sulfasalazine in wild-type mice increased by 8-fold, following oral dosing of curcumin, a

425 potent BCRP inhibitor, whereas no change was observed in Bcrp ${ }^{\%}$ mice. ${ }^{80}$ In human, curcumin

426 increased sulfasalazine AUC by 1.8- to 3.2-fold ${ }^{80}$ (Table 2), suggesting that BCRP plays a

427 significant role in limiting the intestinal absorption of sulfasalazine. Of note, sulfasalazine is an

428 MRP2 and P-gp substrate as well, which may limit its intestinal absorption but to a much lower

429 extent than BCRP based on the observations from transporter knockout mice. Furthermore,

430 sulfasalazine is also transported by OATP2B1 in the gut, which is most likely saturated at

431 sulfasalazine's therapeutic dose, and therefore, may not have significant impact on its intestinal

432 absorption. ${ }^{80}$

As discussed above, rosuvastatin is a substrate for multiple uptake and efflux

transporters, including BCRP. A polymorphism in ABCG2 (c.421C>A) results in a significant

435 increase of rosuvastatin plasma AUC ${ }^{15,16}$ (Table S2), supporting its use as a BCRP probe. As

436 inhibition of BCRP may alter both the intestinal absorption and hepatobiliary excretion of

437 rosuvastatin, it can be a useful probe to assess inhibitory effects on both gut and hepatic

438 BCRP. ${ }^{24}$ Differentiation between the contribution of intestinal and hepatic BCRP is possible only

439 if the appropriate study design is used, as discussed in study design section.

- Endogenous Substrates (Potential Biomarker)

To date, no endogenous probe for BCRP has been identified. ${ }^{13}$

Transporter Probe Drug Cocktails

Since many perpetrator drugs inhibit multiple transporters, concurrent administration of

445 a cocktail containing multiple probe drugs at therapeutic or microdose could be an efficient and 446 valuable tool. The cocktail approach has been successfully applied in drug development and 
447 recognized by regulatory agencies to assess DDIs with CYP enzymes. ${ }^{81}$ However, the evaluation and use of dedicated drug cocktails to study transporter-related DDIs is still limited. ${ }^{20,82,83}$ In

4492011 , Maeda, et $\mathrm{al}^{27}$ designed a clinical study to identify the rate-determining process in 450 hepatic elimination of atorvastatin using a microdose cocktail of atorvastatin along with probe 451 substrates for OATP1B (pravastatin) and CYP3A (midazolam). Recently, two transporter probe 452 drug cocktails have been proposed for studying DDIs involving transporters and their interplay 453 with CYP3A. A transporter probe cocktail containing a conventional dose of digoxin $(0.25 \mathrm{mg}, \mathrm{P}-$ 454 gp), rosuvastatin (10 mg, OATP1B, and BCRP), furosemide (5 mg, OAT1/3), and metformin (500 $455 \mathrm{mg}$, OCT2, MATE1/2K) has been evaluated in vitro ${ }^{17}$ and in clinical PK studies ${ }^{84} 18$. In general, 456 the PK of each probe substrate administered in a cocktail was comparable to when dosed 457 individually, except for a small decrease in $\mathrm{C}_{\max }$ of furosemide and a moderate increase in 458 rosuvastatin $C_{\max }(38.6 \%)$ and $A U C$ (43.4\%). A reduction of the dose of metformin (50 $\mathrm{mg}$ or 10

$459 \mathrm{mg}$ ) and furosemide $(1 \mathrm{mg})$ is further recommended to minimize potential interactions 460 between these probes. ${ }^{84}$ Recently, in a new trial where the doses of metformin and 461 furosemide as putative perpetrators were reduced to $10 \mathrm{mg}$ and $1 \mathrm{mg}$, respectively, their DDI 462 effects on rosuvastatin were shown to be eliminated. ${ }^{85}$ Another microdose cocktail has 463 recently been proposed and validated to study DDIs with OATP1B, P-gp, BCRP, and their 464 interplay with CYP3A. ${ }^{19}$ This five-component cocktail contained midazolam (10 $\left.\mu \mathrm{g}, \mathrm{CYP} 3 \mathrm{~A}\right), \mathrm{DE}$ 465 (375 $\mu \mathrm{g}, \mathrm{P}-\mathrm{gp})$, pitavastatin (10 $\mu \mathrm{g}, \mathrm{OATP} 1 \mathrm{~B})$, rosuvastatin (25 $\mu \mathrm{g}, \mathrm{OATP} 1 \mathrm{~B}, \mathrm{BCRP})$ and 466 atorvastatin (50 $\mu \mathrm{g}$, OATP1B, BCRP, P-gp, and CYP3A). Except for DE, which showed a 2-fold 467 higher magnitude of DDIs with P-gp inhibitors versus a conventional dose, likely caused by 468 saturation of gut P-gp, PK and the magnitude of DDIs with other microdosed probe drugs were 469 generally comparable to those at their respective conventional doses. Probe drug cocktails 470 allow the simultaneous assessment of DDI risk for different transporters/enzymes and thus can 471 provide a mechanistic understanding of complex DDIs involving multiple transporters and 472 enzymes. 


\section{MECHANISTIC CONSIDERATIONS AND CHALLENGES OF USING PROBE DRUGS AND ENDOGENOUS BIOMARKERS TO ASSESS TRANSPORTER INHIBITION}

This section describes mechanistic considerations and challenges associated with the use of exogenously administered probe drugs and endogenous biomarkers to study transporter inhibition. Some of the challenges, such as the lack of selectivity towards individual transporters, are common for biomarkers and probe drugs. However, there are also unique challenges. For example, for many endogenous biomarkers, the kinetic determinants of their systemic exposure are poorly understood or defined. These limitations need to be considered when designing clinical studies or extrapolating observed DDIs to new combinations of drugs.

\section{Probe Drugs}

There are multiple factors that need to be considered prior to qualifying a given drug as a useful "probe" for examining the in vivo activity of a transporter of interest, e.g., absence of additional mechanisms (i.e., selectivity) or the availability of candidate probe drugs in a form that can be safely and ethically administered to humans in a feasible manner (Table 1). The paucity of probe drugs possessing sufficient selectivity places a major limitation on the ability to demonstrate the importance of a given transporter (Table 2). As highlighted, in certain instances testing candidate probe substrates and inhibitors in preclinical species may provide valuable information to guide future clinical investigations. Ultimately, the validation of such probes requires multiple rounds of investigation to identify the appropriate study design and the relatively specific substrate/inhibitor sets that can be utilized clinically.

\section{Overlapping Substrate Specificities of Multiple Transporters and Metabolic Enzymes}

Because most transporter probes are substrates of multiple transporters and/or enzymes, there are substantial challenges in selecting a specific probe. As discussed earlier, rosuvastatin is a substrate of BCRP and several other transporters (e.g., OATP1B1, -1B3, -2B1, 
501 NTCP, and OAT3). If a perpetrator drug is an inhibitor of these transporters, observed DDIs may

502 represent a worst-case scenario for rosuvastatin DDIs, but not inhibition by BCRP alone. In such

503 case, a rosuvastatin clinical DDIs need to be interpreted in conjunction with in vitro and other

504 clinical DDI studies with single or multiple transporter probes of interest or endogenous

505 biomarkers. One promising approach to address the overlapping selectivity of transporters and 506 enzymes, and to maximize clinical study design is to use a transporter and enzyme probe drug 507 cocktail, as discussed in the previous section.

In Vivo Quantitation of Transporter Activities

Probe drugs may be used to quantitatively evaluate the effect of an NME on transporter

511 activity in various organs. However, the nature of the biological matrices that can be easily

512 collected (e.g., blood, urine, feces and saliva) often imposes a major limitation on the practical

513 use of probe drugs in such clinical investigations. The use of stable- or radioisotope-labeled

514 micro-tracers administered intravenously offers the opportunity to evaluate the effect of the

515 perpetrator drugs on the bioavailability and total body clearance of probe drugs. However,

516 limited ability to assess drug concentration-time profiles in tissues imposes limitations on

517 understanding some of transporter DDIs where changes in systemic exposure do not

518 necessarily reflect events at the tissue level. ${ }^{24,68,86}$ In such situations, measurement of the

519 tissue concentration-time profiles by non-invasive approaches, such as positron emission 520 tomography (PET), is important for quantifying transporter activities. ${ }^{87}$ The integrated efforts

521 of combining in vitro, imaging and modelling approaches can improve our predictability of 522 tissue concentrations and DDIs. 88,89 
528 addition, translation of the data from healthy subjects to specific populations, such as the 529 subjects with hepatic or renal impairment also remains challenging due to limited information 530 on the change of transporter activity in these populations. ${ }^{90,91}$

\section{Endogenous Biomarkers}

Mechanistic Understanding of the Formation, Disposition, and Elimination of Biomarkers

One of the major challenges in translating response of endogenous biomarkers to the inhibition of drug transporters is the poor understanding of the mechanisms involved in their

536 formation, disposition, and/or elimination. Using OATP1B biomarkers as an example, Figure 2

537 summarizes key elements that need to be considered when interpreting biomarker data.

538 Factors potentially impacting the interpretation of renal transporter biomarker data are shown

539 in Figure S1. They can be broadly categorized into three elements as described below:

540 selectivity, specificity, sensitivity, and intrinsic or dietary factors. Current knowledge on some

541 emerging biomarker candidates is summarized in Table 3, but a considerable amount of

542 relevant information is still missing.

Selectivity and specificity of biomarkers for assessing transporter inhibition needs to be

544 carefully considered, as highlighted in the case of probe drugs, but to date there has been

545 limited clinical validation of the specificity and selectivity of potential biomarkers. Sensitivity of 546 the endogenous biomarker is another key determinant of their utility in assessing transporter 547 function, especially if the endogenous biomarker data are to be used to support the lack of an 548 interaction between an NME and a transporter. Additionally, understanding of both intra- and 549 inter-subject variability of biomarker levels is needed to evaluate the utility of biomarker in 550 capturing weak or moderate transporter inhibitors/DDIs. Some potential endogenous biomarkers, such as bile acids or bilirubin, are associated 552 with either the development of diseases or organ injury; therefore, they are not ideal 553 biomarkers for DDI assessment (Table 1). Additionally, some biomarkers may be derived from 
554 dietary constituents or metabolites, and in that case the potential effects of food should be

555 carefully ruled out. Effect of perpetrator drugs on the biosynthesis of endogenous biomarkers

556 also needs to be considered, as illustrated recently for CPI and creatinine. ${ }^{92,93,94}$

557 Genetic polymorphisms of drug transporters can shed a light on the mechanistic 558 understanding of endogenous biomarker disposition. One salient example is the altered 559 disposition and elimination of CPI and CPIII due to genetic alterations that affect MRP2 (ABCC2) 560 and OATP1B1 (SLCO1B1) transport activities. ${ }^{12}$ In that case, the observed changes in plasma or 561 urine concentrations of these biomarkers may provide quantitative information on the 562 contribution of individual transporters to a given clearance pathway. It is anticipated that the 563 incorporation of such quantitative measures can be particularly useful in verifying 564 physiologically-based pharmacokinetic (PBPK) models to describe the PK of endogenous 565 biomarkers.

One major difference between endogenous biomarkers and probe drugs is that the baseline concentrations of the endogenous biomarkers are determined by the rate of synthesis 570 (as opposed to dose in the case of clinical probe) $\left(R_{\text {in }}\right)$, along with the rate of 571 degradation/elimination $\left(R_{\text {out }}\right)$. When an endogenous biomarker follows first-order elimination, 572 the concentration of the biomarker $(C)$ at any given time can be described as:

$$
\mathrm{dC} / \mathrm{dt}=\mathrm{R}_{\mathrm{in}}-\mathrm{CL} * \mathrm{C}(\text { Equation } 1)
$$

574 Where $\mathrm{CL}$ represents the clearance of the biomarker. Thus, determination of $R_{\text {in }}$ and $C L$ values is 575 the key for quantitative, model-based analysis of biomarker kinetic profiles. When $\mathrm{R}_{\text {in }}$ and $\mathrm{CL}$ 576 are stable over time (i.e., no diurnal fluctuation), the steady-state concentration $\left(\mathrm{C}_{\mathrm{ss}}\right)$ is 577 described as:

$$
C_{s s}=R_{\text {in }} / C L \text { (Equation 2) }
$$


Unlike the probe drugs for which we can control the administered dose, it is challenging to directly estimate $R_{\text {in. }}$. This has a significant implication on a model-based analysis of

581 biomarker profile and subsequent quantitative interpretation of DDI observations. One strategy 582 is to utilize isotope tracers of endogenous biomarker ${ }^{95}$ to determine $\mathrm{C}_{\mathrm{ss}}$ and $\mathrm{CL}$ of a biomarker, 583 and then infer $\mathrm{R}_{\text {in }}$ based on Equation 2. To obtain $\mathrm{CL}$, kinetic profiles after i.v. administration of 584 the biomarker are the most informative. Another approach is to administer isotopic precursor 585 to determine synthesis rate. Alternatively, clinical data for an endogenous biomarker in the 586 presence and absence of a transporter inhibitor can be modeled simultaneously to estimate the 587 rate of biomarker synthesis and elimination clearances, assuming that the inhibitor only affects 588 transporter-mediated $\mathrm{CL}$, with no effect on $\mathrm{R}_{\text {in. }}{ }^{92}$ Currently such information is limited to only a 589 few transporter biomarkers ${ }^{96}$ and more research is needed to fill the gap to better characterize 590 the kinetic behaviors of biomarkers.

Selection of descriptive PK parameters for biomarkers requires careful considerations.

592 The simplest case is a direct evaluation of the changes in pathway-specific clearance, e.g., $\mathrm{CL}_{r}$, 593 when examining effects on renal transporters. Amount of biomarker excreted into urine over a 594 particular time $\left(A_{e}\right)$ can be expressed as follows:

$$
A_{e}=C L_{r} * A U C(\text { Equation 3) }
$$

596
Therefore, measurement of biomarker $A U C$ and $A_{e}$ in a given time interval allows direct calculation of the effect of test drugs on renal clearance of the biomarker.

The systemic level of a biomarker could be used for the evaluation of transporter function in situations where the direct measurement is not possible (e.g., modulation in biliary excretion). In such cases, the time course of the biomarker after administration of a perpetrator drug is critical to allow correct interpretation of the DDI data. This time course will be influenced by the half-life $\left(t_{1 / 2}\right)$ of not only the biomarker (which may be synthesis, absorption, or elimination rate-limited), but also the PK of the transporter inhibitor. For example, if an inhibitor has a long $t_{1 / 2}$, its effect on the transporter will be sustained after it reaches its maximum concentration, and the biomarker concentrations will approach new steady-state in 
606

607

608

609

610

611

612

613

614

615

616

617

618

619

620

621

622

623

624

625

626

627

628

629

accordance with the $t_{1 / 2}$ of the perpetrator drug. In this situation, AUC would be an appropriate metric to interpret changes in transporter function. Figure $\mathbf{3}$ and Supplementary Materials show various simulations under different scenarios to illustrate these points, and the recommendations on the interpretation of systemic exposure of biomarkers.

\section{Other Considerations}

Similar to the clinical probe drugs, there is a potential substrate-dependency in the in vitro transporter $\mathrm{IC}_{50}$ or $\mathrm{K}_{\mathrm{i}}$ values with either different biomarkers and/or biomarkers to substrate drugs. Therefore, translation of DDI data using one biomarker to predict DDI risk with NMEs needs to be fully evaluated assuming the relevance of substrate-dependent phenomenon in vivo. The importance of investigating more than one biomarker is also applicable to the evaluation of inhibitor effect on other transporters. Fully validated bioanalytical methods for reliable and reproducible measurements of biomarkers are critical (Table 1).

IDENTIFICATION AND VALIDATION OF ENDOGENOUS BIOMARKERS FOR TRANSPORTER DDI EVALUATION

The identification of novel, sensitive endogenous biomarkers to assess transporter inhibition in a clinical setting follows a series of sequential steps. Initially, a candidate biomarker can be identified from a broad scope of potential data sources and subsequently narrowed down through steps of hit identification, lead characterization and eventually clinical validation as detailed in the workflow in Figure 4.

\section{In Vitro and Metabolomics Approaches}



approaches to select a candidate endogenous molecule. For example, metabolomics approaches combined with in vitro assays can be used to examine the uptake of endogenous molecules into cells individually expressing transporters of interest following incubation with

634 biological matrices. The utility of these candidate molecules can then be further challenged in systems of increasing complexity such as knockout rodent models, non-human primates and

636 humans following the administration of a potent and relatively selective transport inhibitor.

637 Finally, the candidate biomarker may be examined in larger populations to verify that variability 638 in its plasma concentrations correlate with known genetic polymorphisms affecting the activity 639 of the transporter of interest. However, there are only a few transporters with clinically 640 meaningful genetic polymorphisms, which may limit this approach. ${ }^{15,16}$ Table S3 provides 641 details and examples on each experimental system. Each system will generate matching test

642 and control samples that will be quantified using metabolomics and enable inferential 643 comparison of dozens of endogenous and exogenous metabolites in parallel and generate candidates. The selected molecules should exhibit robust and consistent responses in all available test systems before they can be considered as biomarkers for the transporter being investigated. Transporter Inhibition

The identification of an endogenous biomarker in a clinical setting is aimed at investigating the sensitivity selectivity, and specificity of candidates identified using the steps outlined above. Factors affecting the baseline concentration of a candidate biomarker such as diet, age, exercise, diurnal variation, and disease state may all confound the ability to observe meaningful changes in the biomarker level upon inhibition of an implicated transporter.

655 Similarly, the participation of additional unidentified transporters in the systemic clearance of 656 the candidate biomarker may also pose an additional challenge. Finally, an understanding of the 657 synthetic and catabolic pathways of the candidate biomarker is necessary to ensure that the 
test inhibitor does not acutely nor chronically interfere with either pathway. Mechanistic models that combine rates of synthesis, degradation and transport can be developed as described in previous sections to further verify the practicality of the candidate biomarker and perform power calculations to guide the design of clinical DDI studies, as illustrated recently for CPI. ${ }^{92}$

Further validation of a candidate biomarker can be done by examining the effect of specific transport inhibitors on the biomarker exposure, preferably in a well-controlled crossover study in subjects that have consented to genomic analysis of the suspected transporter that is known to be polymorphic. Inclusion of a validated probe drug in the study is recommended to enable parallel examination of observed effects. The number of individuals participating in a given trial and the length of treatment should be determined following the appropriate statistical and kinetic analysis of the candidate biomarker PK and extent of contribution of the implicated transporter to the overall systemic clearance. Moreover, confirmatory studies should utilize optimized analytical methods and procedures capable of detecting low levels of the biomarker in the relevant biological matrix. Study design considerations are described in detail in the next section. The results of the clinical study should be used to compare the magnitude of changes in biomarker exposure relative to the changes measured for the transporter probe drug for each of the tested inhibitors.

\section{CLINICAL DDI STUDY DESIGN FOR EVALUATION OF TRANSPORTER INHIBITION WITH CLINICAL PROBE DRUGS OR ENDOGENOUS BIOMARKERS}

\section{Probe Drugs}

Due to the complexity of transporter-mediated drug disposition and DDIs, a rational clinical DDI study design is critical to establish whether an NME can act as an in vivo inhibitor of drug transporter(s). Regulatory DDI guidance documents have provided some 
recommendations on the design of clinical DDI studies, which in general, can be applied to transporter DDIs. ${ }^{4-6}$ Additional practical considerations for designing clinical DDI studies using the probe drugs or cocktails highlighted in previous section are discussed below.

\section{Subjects}

Transporter DDI studies are generally conducted in healthy subjects, rather than patients, unless there are safety concerns. Extrapolation of DDI results from healthy subjects to a specific and/or diseased population requires prior knowledge on alternation of transporter expression and/or activity in addition to the changes of relevant physiological parameters. Limited knowledge is currently available in this emerging area to allow direct translation of clinical DDIs to these specific populations ${ }^{91}$. Carriers of certain genetic polymorphisms (e.g., SLCO1B1 c.521T>C and $A B C G 2$ c.421C $>$ A) will have a diminished response to transport inhibitors as previously described. ${ }^{15,16,89}$ In the context of this article, these variants are specifically relevant for pitavastatin for OATP1B1 (SLCO1B1) and rosuvastatin for BCRP (ABCG2). ${ }^{24,97}$ Thus, it is recommended to genotype subjects for SLCO1B1 and ABCG2 prior to enrollment or at least collect such information after the trial to help data analysis and interpretation ${ }^{15}$, e.g., in case outliers are identified. Currently, genetic information may not be available in cocktail DDI studies that are conducted as a nested arm in a large clinical trial (e.g., secondary DDI endpoint in a phase I trial). However, if the DDI under investigation involves OATP1B1 and/or BCRP inhibition, the inclusion of the genetic analysis in study protocols would be helpful to interpret DDI results.

\section{Dose and Dose Regimen}

In general, the doses of probe and perpetrator drugs should be clinically relevant to appropriately characterize the DDIs. Based on this consideration, the maximum approved dose and shortest dosing interval should be used for transporter inhibitors. For probe drugs, 
potential saturation of drug transporters at a given dose (e.g., intestinal P-gp) needs to be considered, as it may reduce the sensitivity of the measurements. Cocktail probes (at either microdose or therapeutic dose) need to be validated with both PK and clinical DDI studies to confirm the translation of the data to clinical DDIs and the lack of interaction between different probes. In some cases, the magnitude of DDIs at microdose level can be higher than those observed at therapeutic dose due to the saturation of transporters at therapeutic doses (especially relevant in the intestine). ${ }^{19}$ In such cases, microdose data could be considered a worst-case scenario for transporter DDIs and observed DDIs may not be directly translated to therapeutic dose for dosing adjustment. ${ }^{19}$ NMEs with complex inhibition/induction liabilities may require single-dose assessment of the inhibitory effects, and combined induction/inhibition effects following chronic administration (e.g., rifampin, an inhibitor of OATP1B and inducer of CYP3A/P-gp ${ }^{98}$ ).

As with all DDI studies, the sequence of administration and the time interval between dosing of probe drug and perpetrator can impact the outcome. For example, when using the prodrug DE as an in vivo probe for intestinal P-gp, oral dosing of the P-gp inhibitor should precede $D E$ administration to ensure maximum exposure considering rapid hydrolysis of $D E$ to the non-P-gp substrate dabigatran. ${ }^{99}$

In most cases, both perpetrator and probe drugs are orally administered which may reflect the clinical setting. However, use of both i.v. and oral dosing of probe drugs or perpetrators may provide additional mechanistic insight into the relative contributions of intestinal vs. hepatic transporters to the observed DDIs. For example, oral rosuvastatin is recommended to evaluate the DDIs resulting from the inhibition of both intestinal and hepatic $B C R P$, whereas i.v. rosuvastatin can be used to evaluate the contribution of hepatic BCRP. ${ }^{24}$ Similarly, i.v. and oral rifampin have been used as a perpetrator to understand the selectivity of pitavastatin (OATP1B) and rosuvastatin (BCRP/OATP1B) as DDI probe drugs for hepatic and intestinal transport activity, respectively. ${ }^{22}$ 
Changes in systemic exposure of probe drugs ( $A \cup C$ and $C_{\max }$ ratio with and without inhibitor) are generally used to describe the extent of transporter DDIs. Besides these parameters, $\mathrm{CL}_{r}$ of probe drugs should also be measured over the PK sampling period when studying renal transporter DDIs. In such cases, urinary $\mathrm{pH}$ should also be measured to understand potential variability of reabsorption for probes with PKa values within urinary $\mathrm{pH}$ range. PD endpoints are generally not included in DDI studies. However, metformin may represent an example that including PD endpoints could help to interpret clinical DDI data and enable rational dose adjustment. ${ }^{42,43}$

\section{Endogenous Biomarkers}

The design of a clinical study to explore changes in the level of a validated endogenous biomarker after administration of an NME will benefit from a clear understanding of biomarker clearance(s). Characterization of such kinetic parameters may require monitoring of the disposition of an endogenous biomarker using radiolabeled or stable isotopes. The availability of quantitative data on disposition mechanisms (metabolic and renal clearance, in vitro transporter kinetics) and rates of synthesis allows the subsequent development of biomarker PBPK models. Such models can be used to simulate the changes in exposure due to the inhibition of transporter(s) and aid in the design of clinical investigations aimed at maximizing the sensitivity of a given biomarker. In all cases, a crossover study design is preferred given the expected variability in the exposure, rate of elimination, and rate of synthesis in humans. The study design should take into consideration the appropriate time frame to collect the matchedsamples based on PBPK simulations conducted in the absence or presence of the test inhibitor.

The use of a standard cut-off value for the change in biomarker exposure may not be 761 possible with all candidate transporters due to variability in the magnitude of interactions. 762 Instead, a systematic increase in the exposure of the biomarker that corresponds to an increase 763 in the dose of the test inhibitor is recommended as a positive indication of an interaction with 
764 the transporter of interest. Ideally, bioanalysis of the biomarker concentration in the biological

765 766

767 768

matrices (e.g., urine, plasma, saliva) can be added onto typical first-in-human investigations aimed at verifying the safety and tolerability of NME that have been identified as transport inhibitors in vitro or in preclinical species. Such studies will provide a comprehensive dataset to verify the dose-dependent change in the exposure of the biomarker for the transporter of interest up to supra-therapeutic dose levels.

Altered transport activity due to genetic polymorphisms may complicate the ability to detect exposure changes of a drug probe and can affect biomarker concentrations at baseline. Therefore, understanding of this covariate on the systemic exposure of the biomarker and associated variability is important. Moreover, the extent of change above baseline during the course of treatment is likely to be lower in subjects with a reduced function allele than in wild type subjects. Prior knowledge on the genetic makeup of subjects participating in the trial would be beneficial for biomarkers of transporters with clinically relevant polymorphism, e.g., SLCO1B1, ABCG2, and SLC22A1 (OCT1), to explain inter-individual variability.

To address multiple sources of inter-individual variability in biomarker baseline concentrations, a cross-over study design in a sufficiently large number of test subjects (based on power calculations) is required to demonstrate statistical significance. Ideally, the biomarker concentration would be monitored at the beginning of the study period and again after 5-7 days to allow for subject acclimation under the clinical trial conditions. Moreover, synchronization of study procedures ensures that potential diurnal fluctuations in the biomarker level in individuals are not drastically affected in the subjects undergoing the study. Subjects would subsequently receive the test inhibitor preferably following an 8-10 hours fast until steady-state exposure is reached. Test inhibitor should be administered in a consistent manner to all test subjects (e.g., oral administration followed by the consumption of $250 \mathrm{~mL}$ of water) and subjects would consume other meals in a standardized fashion to rule out any potential food effect on biomarker and inhibitor PK. In each period of the study, blood samples (or other matrices) will be collected post-dose, the number of samples and time of collection should closely match the PK of the test inhibitor to ensure capturing changes in the biomarker 
792 level when the inhibitor is at $C_{\max }$ and $C_{\text {trough }}$ levels. Additional treatment cycles where the dose

793 of the inhibitor is escalated should be done in a consistent manner and additional sets of blood

794 samples are collected at steady-state levels. Changes in the biomarker exposure that match the 795 inhibitor dose would be assessed. Ideally changes in the biomarker exposure in individual

796 subjects should correlate with the inhibitor dose as an indication that the examined biomarker 797 is suitable to address the inhibition of the transport activity.

\section{RECOMMENDATION AND PERSPECTIVES OF APPLYING PROBE DRUGS AND ENDOGENOUS} BIOMARKERS TO STUDY TRANSPORTER INHIBITION

The utility of probe drugs and endogenous biomarkers to assess inhibition potential of NMEs on drug transporters are summarized in Figure 5. Monitoring plasma and/or urine exposure of endogenous biomarkers for various transporters could be incorporated in early human PK studies, such as phase I dose escalation studies. Most of the biomarkers reported thus far are not fully validated for their sensitivity, selectivity and specificity as endogenous probes of transporters of interest. Therefore, at present time (Figure 5A), in vivo biomarker data can only be used for designing DDI assessment strategy or for prioritizing the clinical DDI studies with probe substrate drugs (as individual or in a cocktail) or with the most relevant concomitant medications. The data need to be interpreted with the understanding that

812 may potentially be confounded by inhibition on the synthesis of the biomarker. Furthermore, 813 lack of interaction between the NME and the biomarker does not ensure one did not occur and 814 additional targeted evaluation of particular DDIs of concern using probe substrate drugs would 815 be warranted. multiple ascending dose phase I studies. We envisage that the use of a sensitive and selective 
biomarker would potentially obviate the need to administer a probe substrate drug in a dedicated DDI study, avoiding unnecessary drug exposure to participants and to reduce cost.

821 The in vivo biomarker data would also be useful to develop and optimize mechanistic PBPK models for predicting unstudied scenarios for dosing recommendation or for informing additional clinical studies. In vivo biomarker data together with clinical DDI results obtained

824 from individual and/or cocktail probe drugs and PBPK modeling can also provide a mechanistic 825 insight to predict complex DDIs involving inhibition of multiple transporters and enzymes. Such

826

828

829

830

831

832 an integrated approach will ensure understanding of the full dose response with respect to transporter inhibition/induction liability of an NME as a perpetrator, while minimizing DDI studies conducted in response to false positive predictions using in vitro data. It is worth noting that continuing efforts to identify and validate new and existing biomarkers are critically needed. Another targeted effort is to identify probe substrate drugs that are suitable for cassette DDI assessment and exhibit high sensitivity to evaluate transporter inhibition, but with minimal potential for mutual interactions between the components of the cocktail. Precompetitive efforts and dedicated consortia may be valuable in coordinating targeted efforts and accelerating the incorporation of biomarkers and probe drug cocktails in drug development.

In summary, multiple endogenous molecules whose exposure is modulated due to interactions with drug transporters have been identified to support the clinical development of safe and effective therapeutics. Ideally, suitable biomarkers would enable gauging the risk of interactions with clinically relevant transporters. In reality, examples of promising candidate biomarkers are currently only being identified and studied for interactions with several hepatic (OATP1B) and renal transporters (OCT2/MATE1/2K, OAT1/3), but there is a considerable increase in published information. There has been a clear absence of candidate biomarkers to examine P-gp and BCRP inhibition, which is likely due to lack or limited involvement of gut P-gp, and BCRP on in vivo disposition of endogenous substrates and the difficulty associated with estimating the extent of individual contribution of gut, hepatic and renal P-gp and BCRP to the systemic clearance of biomarkers. Continued measurement of candidate biomarkers in clinical studies where transporter interactions are anticipated needs to become more widespread. This 
848 is only possible if suitable language is included in early clinical study protocols to ensure 849 adequate consent from the human subjects. This will ultimately enhance the confidence in the 850 suitability of measuring changes in biomarker concentrations as an indicator of potential clinical 851 transporter DDIs from pharmaceutical and regulatory perspectives.

854 DISCLAIMER

855 The contents of this article reflect the views of the authors and should not be construed to 856 represent the FDA's views or policies. No official support or endorsement by the FDA is 857 intended or should be inferred. The mention of commercial products, their sources, or their use 858 in connection with material reported herein is not to be construed as either an actual or 859 implied endorsement of such products by the FDA.

860

861 ACKNOWLEDGEMENT

862 The authors would like to thank Drs. Donald Tweedie, Raymond Evers, Xinning Yang, and 863 members of ITC for their valuable comments. 
FIGURE LEGENDS

Figure 1. Recommended probe drugs for clinical DDI studies to evaluate inhibitory effects of an NME on major drug transporters expressed in gut, liver and kidney and potential endogenous biomarkers for several hepatic and renal transporters.

The criteria for inclusion of probe drugs in this figure are discussed in the STATE-OF-THE ART IN CLINICAL PROBE DRUGS AND POTENTIAL ENDOGENOUS BIOMARKERS FOR CLINICAL TRANSPORTER DDI ASSESSMENT section. The endogenous substrates with clinical DDI evaluation of potent transporter inhibitor(s) have been included into this figure as potential endogenous biomarkers. Digoxin, dabigatran etexilate (DE), and fexofenadine are probe drugs for multidrug resistance protein MDR1 P-glycoprotein (P-gp, $A B C B 1$ ), and sulfasalazine and rosuvastatin for breast cancer resistance protein (BCRP, ABCG2). Pitavastatin, atorvastatin, and rosuvastatin are probe drugs for the organic anion transporting polypeptides OATP1B1 (SLCO1B1) and OATP1B3 (SLCO1B3); Coproporphyrin I (CPI) and CPIII, glycochenodeoxycholate3-O-sulfate (GCDCA-S), conjugated and unconjugated bilirubin (CB and UCB) are potential endogenous biomarkers for OATP1B1 and -1B3. Hexadecanedioate (HDA) and tetradecanedioate (TDA) are potential biomarkers for OATP1B1 (they are not substrates for OATP1B3). Sumatriptan is a probe drug for organic cation transporter 1 (OCT1; SLC22A1). Metformin is a probe drug for organic cation transporter 2 (OCT2, SLC22A2) and multidrug and toxin extrusion protein MATE1 (SLC47A1) and MATE2K (SLC47A2); N1-methylnicotinamide (NMN) and creatinine are potential endogenous biomarkers of OCT2/MATE1/2K. Adefovir is a probe drug for organic anion transporter 1 (OAT1, SLC22A6); taurine is a potential endogenous biomarker for OAT1. Benzylpenicillin is a probe drugs of organic anion transporter 3 (OAT3;

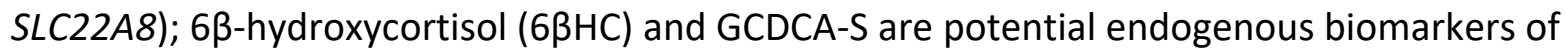
OAT3.

a: Potential endogenous biomarkers with relatively higher selectivity and/or sensitivity for clinical evaluation based on current literature data.

b: Substrates of OATP1B1, but not -1B3.

Green colored circles: uptake transporters; Purple colored circles: efflux transporters. 
894 Figure 2. Mechanistic challenges when developing transporter endogenous biomarker models: OATP1B1/1B3 biomarkers as an example.

Figure 3. Comparison of endogenous biomarkers and probe drugs with different $t_{1 / 2}(A)$ and recommended method for interpreting systemic exposure changes in biomarkers with competitive inhibition of transporters (B-C).

A: Grey lines represent simulated inhibitor concentration and $\%$ of inhibition of the elimination pathway of a probe drug and biomarker. Red, green, and blue lines represent simulated concentration-time profiles of probe drugs and biomarkers in the absence (up to day 6) and presence (on and after day 7 ) of inhibitors, with colors represent different terminal $\mathrm{t}_{1 / 2}$. B-C: See Supplementary Materials for details. ${ }^{*} C_{\max }$ may be influenced by change in other parameters, such as distribution volume, and may not always represent change in clearance.

Figure 4: Workflow for the identification, characterization, and validation of transporter endogenous biomarkers.

a. Recombinant system may be a cellular or a vesicular system that expresses high levels of the 910 target transporter. Transport in the overexpressing system is compared with one in a control 911 system with non-/ or low transporter function.

912 b. One of the two data types should be a mammalian in vivo model with genetically reduced 913 transport function.

914 c. Testing of multiple inhibitors or doses may be required to provide a range of inhibition 915 potency. If a selective inhibitor is not available, multiple inhibitors with differential overlapping 916 selectivity may be required.

917 d. Possible regulatory review process. For example, FDA guidance for drug development 918 tools. $^{100}$ 
920 Figure 5. Examples of current (A) and future (B) considerations regarding the potential utility 921 of endogenous biomarkers (pre-validated (A) and validated(B)) and probe drugs to assess 922 transporter-related inhibition in drug development.

923 a. For transporters without identified biomarkers (e.g., gut transporters), consider to conduct 924 clinical DDI with single or cocktail drug probe(s) at clinically relevant perpetrator dose.

925

926

b. If drugs can potentially inhibit multiple transporters, consider design a drug probe cocktail

927 studies using in vitro and clinically validated probes. If no significant DDIs observed, dedicated 928 clinical DDI studies with single drug probe at conventional doses may not be needed; If 929 significant DDIs observed with selected transporters, dedicated clinical DDI studies with drug 930 probes at clinically relevant exposure (both perpetrator and probes) are needed. 


\section{References:}

1. International Transporter, C., et al. Membrane transporters in drug development. Nat Rev Drug Discov. 9, 215-236 (2010).

2. Tweedie, D., et al. Transporter studies in drug development: experience to date and follow-up on decision trees from the International Transporter Consortium. Clin Pharmacol Ther. 94, 113-125 (2013).

3. Lee, S. C., Arya, V., Yang, X., Volpe, D. A.,\&Zhang, L. Evaluation of transporters in drug development: Current status and contemporary issues. Adv Drug Deliv Rev. 116, 100-118 (2017).

4. U.S. Department of Health and Human Services, Food and Drug Administration, Center for Drug Evaluation and Research (CDER). Clinical Drug Interaction Studies - Study Design, Data Analysis, and Clinical Implications Guidance for Industry. October 2017.

5. European Medicines Agency. Guideline on the investigation of drug interactions. London, UK: EMA; 2013.

6. Ministry of Health, Labour and Welfare, Japan. Guideline of drug interaction studies for drug development and appropriate provision of information. Tokyo, Japan: Ministry of Health; 2014.

7. Zamek-Gliszczynski, M. J., et al. ITC recommendations for transporter kinetic parameter estimation and translational modeling of transport-mediated PK and DDIs in humans. Clin Pharmacol Ther. 94, 64-79 (2013).

8. Rekic, D., et al. Clinical Drug-Drug Interaction Evaluations to Inform Drug Use and Enable Drug Access. J Pharm Sci. 106, 2214-2218 (2017).

9. Yoshida, K., et al. In vitro-In vivo Extrapolation of Metabolism- and Transporter-Mediated DrugDrug Interactions-Overview of Basic Prediction Methods. J Pharm Sci. 106, 2209-2213 (2017).

10. U.S. Department of Health and Human Services, Food and Drug Administration, Center for Drug Evaluation and Research (CDER). In vitro Metabolism- and Transporter- Mediated Drug-Drug Interaction Studies Guidance for Industry. October 2017.

11. Brouwer, K. L., et al. In vitro methods to support transporter evaluation in drug discovery and development. Clin Pharmacol Ther. 94, 95-112 (2013).

12. Chu, X., Chan, G. H.,\&Evers, R. Identification of Endogenous Biomarkers to Predict the Propensity of Drug Candidates to Cause Hepatic or Renal Transporter-Mediated Drug-Drug Interactions. J Pharm Sci. 106, 2357-2367 (2017).

13. Rodrigues, A. D., Taskar, K. S., Kusuhara, H.,\&Sugiyama, Y. Endogenous Probes for Drug Transporters: Balancing Vision With Reality. Clin Pharmacol Ther. (2017).

14. Muller, F., Sharma, A., Konig, J.,\&Fromm, M. F. Biomarkers for In Vivo Assessment of Transporter Function. Pharmacol Rev. 70, 246-277 (2018).

15. Yee, S. W., et al. Influence of Transporter Polymorphisms on Drug Disposition and Response: A Perspective from the International Transporter Consortium. Clin Pharmacol Ther. (2018).

16. Giacomini, K. M., et al. International Transporter Consortium commentary on clinically important transporter polymorphisms. Clin Pharmacol Ther. 94, 23-26 (2013).

17. Ebner, T., Ishiguro, N.,\&Taub, M. E. The Use of Transporter Probe Drug Cocktails for the Assessment of Transporter-Based Drug-Drug Interactions in a Clinical Setting-Proposal of a Four Component Transporter Cocktail. J Pharm Sci. 104, 3220-3228 (2015).

18. Stopfer, P., et al. Pharmacokinetic Evaluation of a Drug Transporter Cocktail Consisting of Digoxin, Furosemide, Metformin, and Rosuvastatin. Clin Pharmacol Ther. 100, 259-267 (2016).

19. Prueksaritanont, T., et al. Validation of a microdose probe drug cocktail for clinical drug interaction assessments for drug transporters and CYP3A. Clin Pharmacol Ther. 101, 519-530 (2017). 
20. Zhang, L.\& Sparreboom, A. Predicting transporter-mediated drug interactions: Commentary on: "Pharmacokinetic evaluation of a drug transporter cocktail consisting of digoxin, furosemide, metformin and rosuvastatin" and "Validation of a microdose probe drug cocktail for clinical drug interaction assessments for drug transporters and CYP3A". Clin Pharmacol Ther. 101, 447-449 (2017).

21. Momper, J. D., Tsunoda, S. M.,\&Ma, J. D. Evaluation of Proposed In vivo Probe Substrates and Inhibitors for Phenotyping Transporter Activity in Humans. J Clin Pharmacol. 56 Suppl 7, S82-98 (2016).

22. Prueksaritanont, T., et al. Pitavastatin is a more sensitive and selective organic anion-transporting polypeptide 1B clinical probe than rosuvastatin. Br J Clin Pharmacol. 78, 587-598 (2014).

23. Elsby, R., Hilgendorf, C.,\&Fenner, K. Understanding the critical disposition pathways of statins to assess drug-drug interaction risk during drug development: it's not just about OATP1B1. Clin Pharmacol Ther. 92, 584-598 (2012).

24. Lee, C. A., et al. Breast cancer resistance protein (ABCG2) in clinical pharmacokinetics and drug interactions: practical recommendations for clinical victim and perpetrator drug-drug interaction study design. Drug Metab Dispos. 43, 490-509 (2015).

25. Pasanen, M. K., Neuvonen, M., Neuvonen, P. J.,\&Niemi, M. SLCO1B1 polymorphism markedly affects the pharmacokinetics of simvastatin acid. Pharmacogenet Genomics. 16, 873-879 (2006).

26. Pasanen, M. K., Fredrikson, H., Neuvonen, P. J.,\&Niemi, M. Different effects of SLCO1B1 polymorphism on the pharmacokinetics of atorvastatin and rosuvastatin. Clin Pharmacol Ther. 82, 726-733 (2007).

27. Maeda, K., et al. Identification of the rate-determining process in the hepatic clearance of atorvastatin in a clinical cassette microdosing study. Clin Pharmacol Ther. 90, 575-581 (2011).

28. van de Steeg, E., et al. Complete OATP1B1 and OATP1B3 deficiency causes human Rotor syndrome by interrupting conjugated bilirubin reuptake into the liver. J Clin Invest. 122, 519-528 (2012).

29. Zhang, W., et al. OATP1B1 polymorphism is a major determinant of serum bilirubin level but not associated with rifampicin-mediated bilirubin elevation. Clin Exp Pharmacol Physiol. 34, 12401244 (2007).

30. van der Deure, W. M., et al. Organic anion transporter 1B1: an important factor in hepatic thyroid hormone and estrogen transport and metabolism. Endocrinology. 149, 4695-4701 (2008).

31. Xiang, X., et al. Effect of SLCO1B1 polymorphism on the plasma concentrations of bile acids and bile acid synthesis marker in humans. Pharmacogenet Genomics. 19, 447-457 (2009).

32. Johnson, A. D., et al. Genome-wide association meta-analysis for total serum bilirubin levels. Human Molecular Genetics. 18, 2700-2710 (2009).

33. Yee, S. W., et al. Metabolomic and Genome-wide Association Studies Reveal Potential Endogenous Biomarkers for OATP1B1. Clin Pharmacol Ther. 100, 524-536 (2016).

34. Takehara, I., et al. Investigation of Glycochenodeoxycholate Sulfate and Chenodeoxycholate Glucuronide as Surrogate Endogenous Probes for Drug Interaction Studies of OATP1B1 and OATP1B3 in Healthy Japanese Volunteers. Pharm Res. 34, 1601-1614 (2017).

35. van de Steeg, E., et al. Organic anion transporting polypeptide 1a/1b-knockout mice provide insights into hepatic handling of bilirubin, bile acids, and drugs. J Clin Invest. 120, 2942-2952 (2010).

36. Shen, H., et al. Coproporphyrins I and III as Functional Markers of OATP1B Activity: In vitro and In vivo Evaluation in Preclinical Species. J Pharmacol Exp Ther. 357, 382-393 (2016).

37. Kunze, A., Ediage, E. N., Dillen, L., Monshouwer, M.,\&Snoeys, J. Clinical Investigation of Coproporphyrins as Sensitive Biomarkers to Predict Mild to Strong OATP1B-Mediated Drug-Drug Interactions. Clin Pharmacokinet. (2018). 
38. Lai, Y., et al. Coproporphyrins in Plasma and Urine Can Be Appropriate Clinical Biomarkers to Recapitulate Drug-Drug Interactions Mediated by Organic Anion Transporting Polypeptide Inhibition. J Pharmacol Exp Ther. 358, 397-404 (2016).

39. Liu, L., et al. A Phase 1, Open-Label, Study to Evaluate the Effect of GDC-0810 on the Pharmacokinetics of Pravastatin in Healthy Female Subjects of Non-Child Bearing Potential. Clin Pharmacol Ther. 101, S75 (2017).

40. Shen, H., et al. Comparative Evaluation of Plasma Bile Acids, Dehydroepiandrosterone Sulfate, Hexadecanedioate, and Tetradecanedioate with Coproporphyrins I and III as Markers of OATP Inhibition in Healthy Subjects. Drug Metab Dispos. 45, 908-919 (2017).

41. Takehara, I., et al. Comparative Study of the Dose-Dependence of OATP1B Inhibition by Rifampicin Using Probe Drugs and Endogenous Substrates in Healthy Volunteers. Pharm Res. 35, 138 (2018).

42. Zamek-Gliszczynski, M. J., Giacomini, K. M.,\&Zhang, L. Emerging Clinical Importance of Hepatic Organic Cation Transporter 1 (OCT1) in Drug Pharmacokinetics, Dynamics, Pharmacogenetic Variability, and Drug Interactions. Clin Pharmacol Ther. (2017).

43. Zamek-Gliszczynski, M. J., et al. ITC Commentary on Metformin Clinical Drug-Drug Interaction Study Design That Enables an Efficacy- and Safety-Based Dose Adjustment Decision. Clin Pharmacol Ther. (2018).

44. Zamek-Gliszczynski, M. J. Transporters in Drug Development: 2018 ITC Recommendations for Emerging Transporters of Clinical Importance. Clin Pharmacol Ther (this issue).

45. Matthaei, J., et al. OCT1 mediates hepatic uptake of sumatriptan and loss-of-function OCT1 polymorphisms affect sumatriptan pharmacokinetics. Clin Pharmacol Ther. 99, 633-641 (2016).

46. Tzvetkov, M. V., Saadatmand, A. R., Bokelmann, K., Meineke, I., Kaiser, R.,\&Brockmoller, J. Effects of OCT1 polymorphisms on the cellular uptake, plasma concentrations and efficacy of the $5-\mathrm{HT}(3)$ antagonists tropisetron and ondansetron. Pharmacogenomics J. 12, 22-29 (2012).

47. Tzvetkov, M. V., et al. Increased Systemic Exposure and Stronger Cardiovascular and Metabolic Adverse Reactions to Fenoterol in Individuals with Heritable OCT1 Deficiency. Clin Pharmacol Ther. (2017).

48. Tzvetkov, M. V., Saadatmand, A. R., Lotsch, J., Tegeder, I., Stingl, J. C.,\&Brockmoller, J. Genetically polymorphic OCT1: another piece in the puzzle of the variable pharmacokinetics and pharmacodynamics of the opioidergic drug tramadol. Clin Pharmacol Ther. 90, 143-150 (2011).

49. Stamer, U. M., Musshoff, F., Stuber, F., Brockmoller, J., Steffens, M.,\&Tzvetkov, M. V. Loss-offunction polymorphisms in the organic cation transporter OCT1 are associated with reduced postoperative tramadol consumption. Pain. 157, 2467-2475 (2016).

50. Tzvetkov, M. V. OCT1 pharmacogenetics in pain management: is a clinical application within reach? Pharmacogenomics. 18, 1515-1523 (2017).

51. Chen, L., et al. OCT1 is a high-capacity thiamine transporter that regulates hepatic steatosis and is a target of metformin. Proc Natl Acad Sci U S A. 111, 9983-9988 (2014).

52. Ashokkumar, B., Vaziri, N. D.,\&Said, H. M. Thiamin uptake by the human-derived renal epithelial (HEK-293) cells: cellular and molecular mechanisms. American Journal of Physiology: Renal Physiology. 291, F796-805 (2006).

53. Kato, K., et al. Investigation of endogenous compounds for assessing the drug interactions in the urinary excretion involving multidrug and toxin extrusion proteins. Pharm Res. 31, 136-147 (2014).

54. Kim, H. I., et al. Fine Mapping and Functional Analysis Reveal a Role of SLC22A1 in Acylcarnitine Transport. American Journal of Human Genetics. 101, 489-502 (2017).

55. Suhre, K., et al. Human metabolic individuality in biomedical and pharmaceutical research. Nature. 477, 54-60 (2011). 
56. Maeda, K., et al. Inhibitory effects of p-aminohippurate and probenecid on the renal clearance of adefovir and benzylpenicillin as probe drugs for organic anion transporter (OAT) 1 and OAT3 in humans. Eur J Pharm Sci. 59, 94-103 (2014).

57. Imaoka, T., Kusuhara, H., Adachi, M., Schuetz, J. D., Takeuchi, K.,\&Sugiyama, Y. Functional involvement of multidrug resistance-associated protein 4 (MRP4/ABCC4) in the renal elimination of the antiviral drugs adefovir and tenofovir. Mol Pharmacol. 71, 619-627 (2007).

58. Mathialagan, S., Piotrowski, M. A., Tess, D. A., Feng, B., Litchfield, J.,\&Varma, M. V. Quantitative Prediction of Human Renal Clearance and Drug-Drug Interactions of Organic Anion Transporter Substrates Using In vitro Transport Data: A Relative Activity Factor Approach. Drug Metab Dispos. 45, 409-417 (2017).

59. Tsuruya, Y., et al. Investigation of Endogenous Compounds Applicable to Drug-Drug Interaction Studies Involving the Renal Organic Anion Transporters, OAT1 and OAT3, in Humans. Drug Metab Dispos. 44, 1925-1933 (2016).

60. Jadavji, N. M., Emmerson, J. T., MacFarlane, A. J., Willmore, W. G.,\&Smith, P. D. B-vitamin and choline supplementation increases neuroplasticity and recovery after stroke. Neurobiology of Disease. 103, 89-100 (2017).

61. Peng, C. C., Templeton, I., Thummel, K. E., Davis, C., Kunze, K. L.,\&Isoherranen, N. Evaluation of 6beta-hydroxycortisol, 6beta-hydroxycortisone, and a combination of the two as endogenous probes for inhibition of CYP3A4 in vivo. Clin Pharmacol Ther. 89, 888-895 (2011).

62. Imamura, Y., et al. 6beta-Hydroxycortisol is an endogenous probe for evaluation of drug-drug interactions involving a multispecific renal organic anion transporter, OAT3/SLC22A8, in healthy subjects. Drug Metab Dispos. 42, 685-694 (2014).

63. Shen, H., et al. Discovery and Validation of Pyridoxic Acid and Homovanillic Acid as Novel Endogenous Plasma Biomarkers of Organic Anion Transporter (OAT) 1 and OAT3 in Cynomolgus Monkeys. Drug Metab Dispos. 46, 178-188 (2018).

64. Liang, X.\& Giacomini, K. M. Transporters Involved in Metformin Pharmacokinetics and Treatment Response. J Pharm Sci. 106, 2245-2250 (2017).

65. Oh, J., et al. Inhibition of the multidrug and toxin extrusion (MATE) transporter by pyrimethamine increases the plasma concentration of metformin but does not increase antihyperglycaemic activity in humans. Diabetes Obes Metab. 18, 104-108 (2016).

66. Kusuhara, H., et al. Effects of a MATE protein inhibitor, pyrimethamine, on the renal elimination of metformin at oral microdose and at therapeutic dose in healthy subjects. Clin Pharmacol Ther. 89, 837-844 (2011).

67. Gong, L., Goswami, S., Giacomini, K. M., Altman, R. B.,\&Klein, T. E. Metformin pathways: pharmacokinetics and pharmacodynamics. Pharmacogenet Genomics. 22, 820-827 (2012).

68. Hibma, J. E., et al. The Effect of Famotidine, a MATE1-Selective Inhibitor, on the Pharmacokinetics and Pharmacodynamics of Metformin. Clin Pharmacokinet. 55, 711-721 (2016).

69. Ito, S., et al. N-methylnicotinamide is an endogenous probe for evaluation of drug-drug interactions involving multidrug and toxin extrusions (MATE1 and MATE2-K). Clin Pharmacol Ther. 92, 635-641 (2012).

70. Muller, F., et al. N(1)-methylnicotinamide as an endogenous probe for drug interactions by renal cation transporters: studies on the metformin-trimethoprim interaction. Eur J Clin Pharmacol. 71, 85-94 (2015).

71. Bergagnini-Kolev, M. C., Hebert, M. F., Easterling, T. R.,\&Lin, Y. S. Pregnancy Increases the Renal Secretion of N(1)-methylnicotinamide, an Endogenous Probe for Renal Cation Transporters, in Patients Prescribed Metformin. Drug Metab Dispos. 45, 325-329 (2017). 
72. Weber, W., Toussaint, S., Looby, M., Nitz, M.,\&Kewitz, H. System analysis in multiple dose kinetics: evidence for saturable tubular reabsorption of the organic cation N1-methylnicotinamide in humans. Journal of Pharmacokinetics and Biopharmaceutics. 19, 553-574 (1991).

73. Chu, X., Bleasby, K., Chan, G. H., Nunes, I.,\&Evers, R. The Complexities of Interpreting Reversible Elevated Serum Creatinine Levels in Drug Development: Does a Correlation with Inhibition of Renal Transporters Exist? Drug Metab Dispos. 44, 1498-1509 (2016).

74. Nader, A. M.\& Foster, D. R. Suitability of digoxin as a P-glycoprotein probe: implications of other transporters on sensitivity and specificity. J Clin Pharmacol. 54, 3-13 (2014).

75. Lee, C. A., Kalvass, J. C., Galetin, A.,\&Zamek-Gliszczynski, M. J. ITC commentary on the prediction of digoxin clinical drug-drug interactions from in vitro transporter assays. Clin Pharmacol Ther. 96, 298-301 (2014).

76. Cvetkovic, M., Leake, B., Fromm, M. F., Wilkinson, G. R.,\&Kim, R. B. OATP and P-glycoprotein transporters mediate the cellular uptake and excretion of fexofenadine. Drug Metab Dispos. 27, 866-871 (1999).

77. Shirasaka, Y., et al. Concentration-dependent effect of naringin on intestinal absorption of beta(1)-adrenoceptor antagonist talinolol mediated by p-glycoprotein and organic anion transporting polypeptide (Oatp). Pharm Res. 26, 560-567 (2009).

78. Hartter, S., et al. Decrease in the oral bioavailability of dabigatran etexilate after co-medication with rifampicin. Br J Clin Pharmacol. 74, 490-500 (2012).

79. Chu, X., et al. Dabigatran Etexilate and Digoxin: a Critical Comparison as Clinical Probes for P-gp Inhibition Evaluation. Clin Pharmacol Ther (this issue).

80. Kusuhara, H., et al. Pharmacokinetic interaction study of sulphasalazine in healthy subjects and the impact of curcumin as an in vivo inhibitor of BCRP. Br J Pharmacol. 166, 1793-1803 (2012).

81. Zhou, H., Tong, Z.,\&McLeod, J. F. "Cocktail" approaches and strategies in drug development: valuable tool or flawed science? J Clin Pharmacol. 44, 120-134 (2004).

82. Lenuzza, N., et al. Safety and pharmacokinetics of the CIME combination of drugs and their metabolites after a single oral dosing in healthy volunteers. Eur J Drug Metab Pharmacokinet. 41, 125-138 (2016).

83. Kashihara, Y., et al. Small-Dosing Clinical Study: Pharmacokinetic, Pharmacogenomic (SLCO2B1 and ABCG2), and Interaction (Atorvastatin and Grapefruit Juice) Profiles of 5 Probes for OATP2B1 and BCRP. J Pharm Sci. 106, 2688-2694 (2017).

84. Stopfer, P., et al. Effects of Metformin and Furosemide on Rosuvastatin Pharmacokinetics in Healthy Volunteers: Implications for Their Use as Probe Drugs in a Transporter Cocktail. Eur J Drug Metab Pharmacokinet. (2017).

85. Stopfer, P., et al. Optimization of a drug transporter probe cocktail: potential screening tool for transporter-mediated drug-drug interactions. Br J Clin Pharmacol. (2018).

86. Watanabe, T., Kusuhara, H., Maeda, K., Shitara, Y.,\&Sugiyama, Y. Physiologically based pharmacokinetic modeling to predict transporter-mediated clearance and distribution of pravastatin in humans. J Pharmacol Exp Ther. 328, 652-662 (2009).

87. Langer, O. Use of PET Imaging to Evaluate Transporter-Mediated Drug-Drug Interactions. J Clin Pharmacol. 56 Suppl 7, S143-156 (2016).

88. Guo.\& et. al. Advancing Predictions of Tissue and Intracellular Drug Concentrations Using In vitro, Imaging and PBPK Modeling Approaches. Clin Pharmacol Ther (this issue).

89. Chu, X., et al. Intracellular drug concentrations and transporters: measurement, modeling, and implications for the liver. Clin Pharmacol Ther. 94, 126-141 (2013).

90. Miners, J. O., Yang, X., Knights, K. M.,\&Zhang, L. The Role of the Kidney in Drug Elimination: Transport, Metabolism, and the Impact of Kidney Disease on Drug Clearance. Clin Pharmacol Ther. 102, 436-449 (2017). 
91. Evers, R., et al. Disease-Associated Changes in Drug Transporters May Impact the Pharmacokinetics and/or Toxicity of Drugs: A White Paper from the International Transporter Consortium. Clin Pharmacol Ther. (2018).

92. Barnett, S., et al. Gaining Mechanistic Insight Into Coproporphyrin I as Endogenous Biomarker for OATP1B-Mediated Drug-Drug Interactions Using Population Pharmacokinetic Modeling and Simulation. Clin Pharmacol Ther. (2017).

93. Agarwal, R., Hynson, J. E., Hecht, T. J., Light, R. P.,\&Sinha, A. D. Short-term vitamin D receptor activation increases serum creatinine due to increased production with no effect on the glomerular filtration rate. Kidney Int. 80, 1073-1079 (2011).

94. Weir, M. R. Short-term effects of vitamin D receptor activation on serum creatinine, creatinine generation, and glomerular filtration. Kidney Int. 80, 1016-1017 (2011).

95. Wolfe, R. R.\& Chinkes, D. L. Isotope tracers in metabolic research: principles and practice of kinetic analysis (John Wiley \& Sons: 2005).

96. Koskelo, P.\& Kekki, M. Multicompartment analysis of 14C-labelled coproporphyrin and uroporphyrin kinetics in human beings. Annals of Clinical Research. 8 Suppl 17, 198-202 (1976).

97. Tsamandouras, N., et al. Identification of the effect of multiple polymorphisms on the pharmacokinetics of simvastatin and simvastatin acid using a population-modeling approach. Clin Pharmacol Ther. 96, 90-100 (2014).

98. Reitman, M. L., et al. Rifampin's acute inhibitory and chronic inductive drug interactions: experimental and model-based approaches to drug-drug interaction trial design. Clin Pharmacol Ther. 89, 234-242 (2011).

99. Hartter, S., Sennewald, R., Nehmiz, G.,\&Reilly, P. Oral bioavailability of dabigatran etexilate (Pradaxa $((\mathrm{R}))$ ) after co-medication with verapamil in healthy subjects. Br J Clin Pharmacol. 75, 1053-1062 (2013).

100. Guidance for Industry and FDA Staff on the Qualification Process for Drug Development Tools, U.S. Department of Health and Human Services Food and Drug Administration Center for Drug Evaluation and Research (CDER) January 2014.

101. Chen, Y., et al. Effect of a single-dose rifampin on the pharmacokinetics of pitavastatin in healthy volunteers. Eur J Clin Pharmacol. 69, 1933-1938 (2013).

102. Kim, S. J., et al. Clarification of the Mechanism of Clopidogrel-Mediated Drug-Drug Interaction in a Clinical Cassette Small-dose Study and Its Prediction Based on In vitro Information. Drug Metab Dispos. 44, 1622-1632 (2016).

103. Wu, H. F., et al. Rosuvastatin Pharmacokinetics in Asian and White Subjects Wild Type for Both OATP1B1 and BCRP Under Control and Inhibited Conditions. J Pharm Sci. 106, 2751-2757 (2017).

104. Lau, Y. Y., Huang, Y., Frassetto, L.,\&Benet, L. Z. effect of OATP1B transporter inhibition on the pharmacokinetics of atorvastatin in healthy volunteers. Clin Pharmacol Ther. 81, 194-204 (2007).

105. He, Y. J., et al. Rifampicin alters atorvastatin plasma concentration on the basis of SLCO1B1 521T>C polymorphism. Clinica Chimica Acta. 405, 49-52 (2009).

106. Cheng, Z., et al. Hydrophilic anti-migraine triptans are substrates for OATP1A2, a transporter expressed at human blood-brain barrier. Xenobiotica. 42, 880-890 (2012).

107. Tfelt-Hansen, P.\& Hougaard, A. Sumatriptan: a review of its pharmacokinetics, pharmacodynamics and efficacy in the acute treatment of migraine. Expert Opin Drug Metab Toxicol. 9, 91-103 (2013).

108. Prescribing Information of IMITREX.

109. Jalava, K. M., Partanen, J.,\&Neuvonen, P. J. Itraconazole decreases renal clearance of digoxin. Ther Drug Monit. 19, 609-613 (1997).

110. Vermeer, L. M., Isringhausen, C. D., Ogilvie, B. W.,\&Buckley, D. B. Evaluation of Ketoconazole and Its Alternative Clinical CYP3A4/5 Inhibitors as Inhibitors of Drug Transporters: The In vitro Effects 
of Ketoconazole, Ritonavir, Clarithromycin, and Itraconazole on 13 Clinically-Relevant Drug Transporters. Drug Metab Dispos. 44, 453-459 (2016). 
- Supplementary Section 1

- Table S1.

- Table S2.

- Table S3.

- Supplementary Materials

- $\quad$ Figure S1.

- $\quad$ Figure S2. 
Table 1. Ideal features of transported probe drugs or biomarkers for the evaluation of clinical DDIs.

- Transport. Active transport and transport kinetics of the clinical probe or biomarker are demonstrated using suitable in vitro assays. Active transport significantly contributes to the in vitro and in vivo clearance

- Selectivity and Specificity. The contribution of the transporter of interest to the overall clearance of the candidate clinical probe or biomarker is clearly established kinetically. Transport represents the rate-limiting step to overall systemic clearance despite the presence of downstream disposition pathways (e.g., metabolism).

- Sensitivity. Active transport significantly contributes to the in vitro or in vivo clearance and can be demonstrated clinically from known genetic polymorphisms or DDI studies that affect the transport activity. The extent of change in exposure due to inhibition correlates with the potency of co-administered inhibitors and can be measured with high sensitivity and accuracy using robust validated bioanalytical methods.

- In vivo PK. Detailed characterization of the PK parameters including various disposition (and formation) pathways. The PK profile should provide sufficient flexibility to allow demonstration of changes in exposure preferably following common early clinical study protocols

- Additional desirable features

a. Predictability with modeling. The magnitude of change in PK profiles is predictable using PBPK models.

b. Regulatory acceptance. The clinical probe and biomarker are accepted by regulatory agencies in support of in vitro data generation, IVIVE exercises, definitive clinical DDI assessment, and product labeling.

c. Administration to subjects. Clinical drug probe can be administered using multiple routes and in combination with other agents as a cocktail. Changes in clinical drug PK corresponds to those of candidate biomarkers that utilize the same transport mechanism

d. Candidate biomarker concentrations are not significantly altered due to physiological or pathophysiological changes when compared to those when transport activity is impaired

e. Low likelihood of interference with rates of synthesis or catabolism of candidate biomarkers due to transporter inhibition 
Table 2: Examples of probe drugs for OATP1B, OCT1, P-gp, BCRP, OAT1, OAT3, OCT2, MATE1, and MATE2K for clinical DDI evaluation.

\begin{tabular}{|c|c|c|c|c|c|c|}
\hline \multirow{2}{*}{$\begin{array}{c}\text { Probe drugs } \\
\text { (therapeutic class) }\end{array}$} & \multirow{2}{*}{$\begin{array}{l}\text { In vitro transport } \\
\text { profile/kinetic } \\
\text { parameters }\left(\mathrm{K}_{\mathrm{m}}\right)^{\mathrm{a}}\end{array}$} & \multirow{2}{*}{$\begin{array}{c}\text { Key human } \\
\text { ADME property } \\
\text { and } \mathrm{C}_{\max } \text { and } \\
\mathrm{C}_{\operatorname{maxu}} \text { at } \\
\text { therapeutic dose }\end{array}$} & \multicolumn{3}{|c|}{ Clinical DDI with known inhibitors } & \multirow{2}{*}{ References } \\
\hline & & & $\begin{array}{c}\text { Inhibitor (dose } \\
\text { regimen), } \mathrm{C}_{\max }, \mathrm{C}_{\operatorname{maxu}} \text {, } \\
\mathrm{I}_{2}, \text { and/or } \mathrm{I}_{\mathrm{inmax}}\end{array}$ & $\begin{array}{c}\text { PK Change } \\
\text { (inhibitor/control) }\end{array}$ & $\begin{array}{l}\text { Inhibitor selectivity } \\
\qquad\left(\mathrm{IC}_{50} \text { or } \mathrm{K}_{\mathrm{i}}\right)^{\mathrm{a}}\end{array}$ & \\
\hline \multicolumn{7}{|c|}{ OATP1B1/OATP1B3 } \\
\hline $\begin{array}{l}\text { Pitavastatin } \\
\text { (HMG-CoA } \\
\text { reductase } \\
\text { inhibitor) }\end{array}$ & 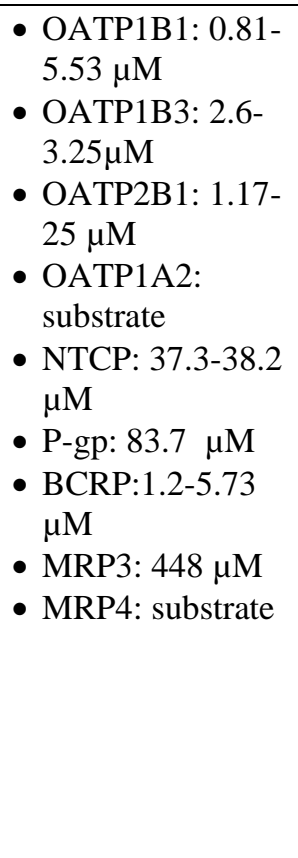 & $\begin{array}{l}\text { - F: } 51 \% \\
\text { PPB: 99.5- } \\
\text { 99.6\% } \\
\text { - } \mathrm{V}_{\mathrm{d}}: 148 \mathrm{~L} \\
\text { - Metabolism: } \\
\text { CYP2C9 } \\
\text { (marginally), } \\
\text { CYP2C8 } \\
\text { (lesser), and } \\
\text { UGT1A3 and } \\
\text { UGT2B7 } \\
\text { (formed major } \\
\text { metabolites in } \\
\text { human plasma) } \\
\text { - Elimination: } \\
\text { renal (15\%); } \\
\text { feces (79\%) } \\
\text { - } \mathrm{t}_{1 / 2}: 12 \mathrm{hrs} \\
\text { - } \mathrm{C}_{\max }: 29.6 \mathrm{nM} \text {; } \\
\mathrm{C}_{\operatorname{maxu}}: 0.13 \mathrm{nM} \\
\text { (2mg oral SD) }\end{array}$ & $\begin{array}{l}\text { Rifampin (iv or po } \\
600 \mathrm{mg} \text { SD) } \\
\text { PO: } \\
\text { - } \mathrm{C}_{\text {max }}: 12.2-29.8 \mu \mathrm{M} \\
\text { - } \mathrm{C}_{\text {maxu }}: 3.04-7.38 \\
\quad \mu \mathrm{M} \\
\text { - } \mathrm{I}_{2}: 2916 \mu \mathrm{M} \\
\text { - } \mathrm{I}_{\text {inmaxu }}: 15.2-19.5 \\
\mu \mathrm{M} \\
\text { IV: } \\
\text { - } \mathrm{C}_{\text {max }}: 24.3 \mu \mathrm{M} \\
\text { - } \mathrm{C}_{\text {maxu }}: 6.08 \mu \mathrm{M}\end{array}$ & $\begin{array}{l}\text { IV Rifampin: } \\
\text { - AUCR: } 7.55 \\
\text { - } \mathrm{C}_{\max } \mathrm{R}: 6.00 \\
\\
\text { PO Rifampin: } \\
\text { - AUCR: 4.22- } \\
\quad 6.4 \\
\text { - } \mathrm{C}_{\max } \mathrm{R}: 4.08-9.2\end{array}$ & 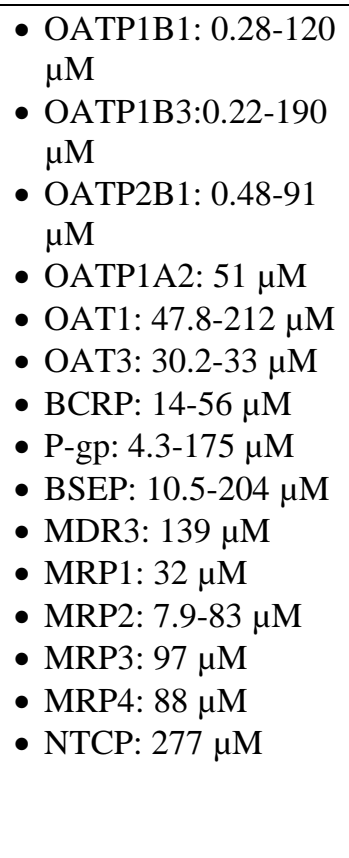 & $22,101,102$ \\
\hline
\end{tabular}




\begin{tabular}{|c|c|c|c|c|c|}
\hline $\begin{array}{l}\text { Probe drugs } \\
\text { (therapeutic class) }\end{array}$ & $\begin{array}{l}\text { In vitro transport } \\
\text { profile/kinetic }\end{array}$ & $\begin{array}{c}\text { Key human } \\
\text { ADME property } \\
\text { and } C_{\max } \text { and }\end{array}$ & \multicolumn{2}{|c|}{ Clinical DDI with known inhibitors } & References \\
\hline $\begin{array}{l}\text { Rosuvastatin } \\
\text { (HMG-CoA } \\
\text { reductase } \\
\text { inhibitor) }\end{array}$ & 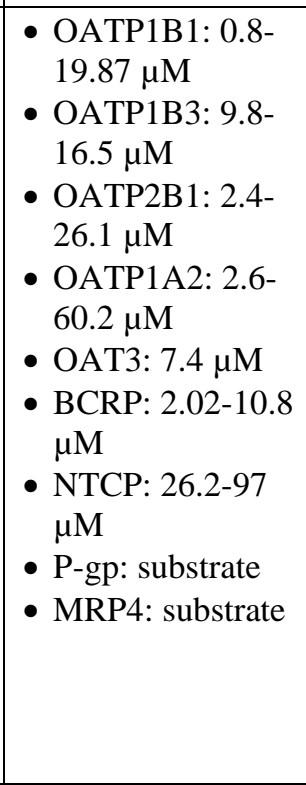 & $\begin{array}{l}\text { - F: } 20 \% \\
\text { - PPB: } 88 \% \\
\text { - } \mathrm{V}_{\mathrm{d}}: 134 \mathrm{~L} \\
\text { - Metabolism: } \\
\text { not extensively } \\
\text { metabolized } \\
\text { ( 10\% as } \\
\text { metabolite). } \\
\text { CYP2C9 } \\
\text { (major) } \\
\text { - Elimination: } \\
\text { renal }(28 \%) ; \\
\text { feces }(72 \%) \\
\text { - } \mathrm{t}_{1 / 2}: 19 \mathrm{hrs} \\
\text { - } \mathrm{C}_{\max }: 4.6 \mathrm{nM} ; \\
\mathrm{C}_{\operatorname{maxu}} 0.55 \mathrm{nM} \\
\text { (10 mg oral } \\
\text { QD for } 10 \\
\text { days) }\end{array}$ & $\begin{array}{l}\text { Rifampin (iv or po } \\
\text { 600mg SD) } \\
\text { PO: } \\
\text { - } \mathrm{C}_{\text {max }}: 12.2-30.6 \mu \mathrm{M} \\
\text { - } \mathrm{C}_{\operatorname{maxu}}: 3.04-7.65 \\
\mu \mathrm{M} \\
\text { - } \mathrm{I}_{2}: 2916 \mu \mathrm{M} \\
\text { - } \mathrm{I}_{\text {inmaxu }}: 15.2-19.8 \\
\mu \mathrm{M} \\
\mathrm{IV}: \\
\text { - } \mathrm{C}_{\max }: 24.3 \mu \mathrm{M} \\
\text { - } \mathrm{C}_{\operatorname{maxu}}: 6.08 \mu \mathrm{M}\end{array}$ & $\begin{array}{l}\text { IV Rifampin: } \\
\text { - AUCR: 3.21- } \\
3.37 \\
\text { - } \mathrm{C}_{\max } \mathrm{R}: 5.51- \\
8.55 \\
\\
\text { PO Rifampin: } \\
\text { - AUCR: 4.37- } \\
\quad 4.8 \\
\text { - } \mathrm{C}_{\max } \mathrm{R}: 9.93- \\
13.2\end{array}$ & $19,22,38,103$ \\
\hline $\begin{array}{l}\text { Atorvastatin } \\
\text { (HMG-CoA } \\
\text { reductase } \\
\text { inhibitor) }\end{array}$ & 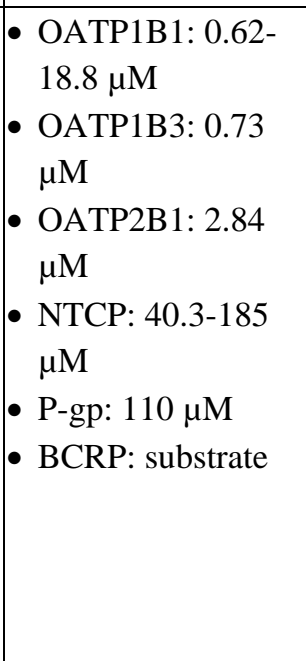 & $\begin{array}{l}\text { - F: } 14 \% \\
\text { PPB: } \geq 98 \% \\
\text { P } \mathrm{V}_{\mathrm{d}}: 381 \mathrm{~L} \\
\text { - Metabolism: } \\
\text { extensively } \\
\text { metabolized. } \\
\text { CYP3A4 } \\
\text { (major) } \\
\text { - Elimination: } \\
\text { primarily into } \\
\text { bile (both } \\
\text { parent and } \\
\text { metabolites); } \\
\text { renal }(<2 \%) ; \\
\mathrm{t}_{1 / 2}: 19.5 \mathrm{hrs} \\
\mathrm{C}_{\max }: 12.3 \mathrm{nM} ;\end{array}$ & $\begin{array}{l}\text { Rifampin (iv or po } \\
600 \mathrm{mg} \text { SD) } \\
\text { - } \mathrm{C}_{\max }: 9.35-22.6 \mu \mathrm{M} \\
\text { - } \mathrm{C}_{\operatorname{maxu}}: 1.41-5.65 \\
\mu \mathrm{M} \\
\text { - } \mathrm{I}_{2}: 2916 \mu \mathrm{M} \\
\text { - } \mathrm{I}_{\text {inmaxu }}: 8.70-17.8 \\
\mu \mathrm{M} \\
\text { IV: } \\
\text { - } \mathrm{C}_{\max }: 17.1 \mu \mathrm{M} \\
\text { - } \mathrm{C}_{\max }: 4.28 \mu \mathrm{M}\end{array}$ & $\begin{array}{l}\text { IV Rifampin: } \\
\text { - AUCR: 7.82 } \\
\text { - } \mathrm{C}_{\max } \mathrm{R}: 10.5 \\
\\
\text { PO Rifampin: } \\
\text { - AUCR: 8.51-12 } \\
\text { - } \mathrm{C}_{\max } \mathrm{R}: 14.9- \\
\quad 21.1 \\
\end{array}$ & $19,27,104,105$ \\
\hline
\end{tabular}




\begin{tabular}{|c|c|c|c|c|c|c|}
\hline $\begin{array}{c}\text { Probe drugs } \\
\text { (therapeutic class) }\end{array}$ & $\begin{array}{l}\text { In vitro transport } \\
\text { profile/kinetic } \\
\text { parameters }\left(\mathrm{K}_{\mathrm{m}}\right)^{\mathrm{a}}\end{array}$ & $\begin{array}{c}\text { Key human } \\
\text { ADME property } \\
\text { and } \mathrm{C}_{\max } \text { and }\end{array}$ & \multicolumn{3}{|c|}{ Clinical DDI with known inhibitors } & \multirow[t]{2}{*}{ Reference } \\
\hline & & $\begin{array}{l}\mathrm{C}_{\operatorname{maxu}}: 0.25 \mathrm{nM} \\
(20 \mathrm{mg} \text { oral } \\
\text { QD for } 14 \\
\text { days) }\end{array}$ & & & & \\
\hline \multicolumn{7}{|l|}{ OCT1 } \\
\hline $\begin{array}{l}\text { Sumatritpan } \\
((5- \\
\text { hydroxytriptamine } \\
\text { receptor agonist } \\
\text { for migraine } \\
\text { treatment) }\end{array}$ & $\begin{array}{l}\text { - OCT1: } 55.4 \mu \mathrm{M} \\
\text { - OATP1A2: } \\
94.5 \mu \mathrm{M}\end{array}$ & $\begin{array}{l}\text { - F: } 15 \% \\
\text { - PPB: } 14-21 \% \\
\text { - } \mathrm{V}_{\mathrm{d}}: 2.4 \mathrm{~L} / \mathrm{kg} \\
\text { Metabolism: } \\
\text { extensively } \\
\text { metabolized by } \\
\text { monoamine } \\
\text { oxidase type A } \\
\text { (MAOA) } \\
\text { - Elimination: } \\
\text { primarily in } \\
\text { urine } 60 \% \text { as } \\
\text { the major } \\
\text { metabolite IAA } \\
\text { (3\% } \\
\text { unchanged); } \\
\text { fecal ( 40\%); } \\
\text { - } \mathrm{t}_{1 / 2}: 2.5 \mathrm{hrs}\end{array}$ & $\begin{array}{l}\text { No clinical DDI } \\
\text { studies are available } \\
\text { with OCT1 inhibitors } \\
\text { PGx study compared } \\
\text { OCT1*1-*2 (active) } \\
\text { to OCT1*3-*6 } \\
\text { (deficient) }\end{array}$ & $\begin{array}{l}\text { AUCR: } 2.2 \\
\text { (higher in } \\
\text { subjects with } \\
\text { two deficient } \\
\text { alleles relative } \\
\text { to one or more } \\
\text { active alleles) } \\
\mathrm{C}_{\max } \mathrm{R}: 1.8 \\
\text { (higher in } \\
\text { subjects with } \\
\text { two deficient } \\
\text { alleles relative } \\
\text { to one or more } \\
\text { active alleles) }\end{array}$ & NA & $45,106-108$ \\
\hline
\end{tabular}




\begin{tabular}{|c|c|c|c|c|c|c|}
\hline $\begin{array}{c}\text { Probe drugs } \\
\text { (therapeutic class) }\end{array}$ & $\begin{array}{l}\text { In vitro transport } \\
\text { profile/kinetic } \\
\text { parameters }\left(\mathrm{K}_{\mathrm{m}}\right)^{\mathrm{a}}\end{array}$ & $\begin{array}{c}\text { Key human } \\
\text { ADME property } \\
\text { and } \mathrm{C}_{\max } \text { and } \\
\mathrm{C}\end{array}$ & \multicolumn{3}{|c|}{ Clinical DDI with known inhibitors } & References \\
\hline \multicolumn{7}{|l|}{ P-gp } \\
\hline \multirow[t]{2}{*}{$\begin{array}{l}\text { Digoxin (Cardiac/ } \\
\text { digitalis } \\
\text { glycosides) }\end{array}$} & \multirow[t]{2}{*}{$\begin{array}{l}\text { - P-gp: } 73-220 \mu \mathrm{M} \\
\text { - OATP4C1: } 7.8 \\
\mu \mathrm{M}\end{array}$} & \multirow{2}{*}{\begin{tabular}{|l} 
- F: $60-80 \%$ \\
- PPB: $25 \%$ \\
- $\mathrm{V}_{\mathrm{d}}: 3.12 \mathrm{~L} / \mathrm{kg}$ \\
- Metabolism: \\
minimal (16\% \\
of dose by non- \\
CYP \\
metabolism) \\
- Elimination: \\
renal (50-70\% \\
as unchanged \\
drug, after IV \\
dose) \\
- $\mathrm{t}_{1 / 2}: 39$ hrs \\
- $\mathrm{C}_{\max }: 0.97-2.1$ \\
nM ; $\mathrm{C}_{\operatorname{maxu}}:$ \\
$0.73-2.58 \mathrm{nM}$ \\
(0.25mg oral \\
$\mathrm{SD})$
\end{tabular}} & $\begin{array}{ll}\text { Itraconazole (oral } \\
200 \mathrm{mg} \text { QD x } 5 \text { days) } \\
-\quad \mathrm{C}_{\max }: 746.8 \mathrm{nM} ; \\
- & \mathrm{C}_{\operatorname{maxu}}: 1.49 \mathrm{nM} \\
- & \mathrm{I}_{2}: 1133.7 \mu \mathrm{M} \\
\end{array}$ & $\begin{array}{l}\text { - } \text { AUCR: } 1.68 \\
\text { - } \mathrm{C}_{\max } \text { R: } 1.34\end{array}$ & $\begin{array}{l}\text { - P-gp: 0.05-9.5 } \mu \mathrm{M} \\
\text { - BCRP: } 1.9-10 \mu \mathrm{M} \\
\text { - OATP2B1: } 2.5 \mu \mathrm{M} \\
\text { - OCT1: } 0.74 \mu \mathrm{M} \\
\text { - MRP3: } 2.1 \mu \mathrm{M} \\
\text { - BSEP: } 1.8-3 \mu \mathrm{M}\end{array}$ & $109,110, \mathrm{~g}$ \\
\hline & & & $\begin{array}{l}\text { Verapamil (oral } 80 \\
\text { mg TID x 2-4 weeks } \\
\text { or } 120 \mathrm{mg} \text { TID x } 2 \\
\text { weeks) } \\
\text { - } \mathrm{C}_{\text {avg: }}: 73-132 \mathrm{nM} \\
\text { - } \quad \mathrm{C}_{\text {avg,u }}: 7.3-13.2 \\
\quad \mathrm{nM}^{-} \\
\text {- } \mathrm{I}_{2}: 704-1056 \mu \mathrm{M}\end{array}$ & $\begin{array}{ll}\text { - } & \text { AUCR: } 1.5 \\
\text { - } & \mathrm{C}_{\max } \mathrm{R}: 1.44- \\
& 1.77 \\
\text { - } & \mathrm{CL}_{\text {renal }} \mathrm{R}: 1.04- \\
& 1.13 \\
\text { - } & \mathrm{CL}_{\text {biliary }} \mathrm{R}: 0.54 \\
& \end{array}$ & 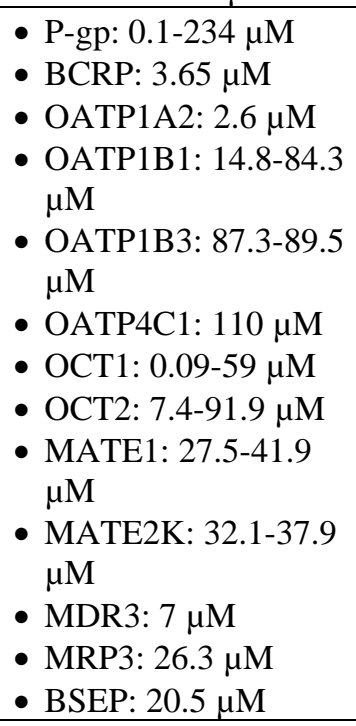 & $\mathrm{g}$ \\
\hline $\begin{array}{l}\text { Fexofenadine } \\
\text { (Histamine H1- } \\
\text { receptor } \\
\text { antagonist) }\end{array}$ & 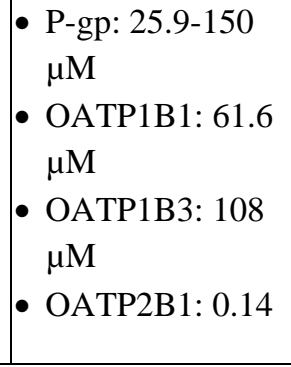 & $\begin{array}{l}\text { - F: NR } \\
\text { PPB: } 60-70 \% \\
\text { - Metabolism: } \\
\text { minimal (5\% of } \\
\text { dose by hepatic } \\
\text { metabolism) } \\
\text { - Elimination: }\end{array}$ & $\begin{array}{l}\text { Itraconazole (oral } \\
50 / 100 / 200 \mathrm{mg} \mathrm{SD} \text {, } \\
\text { or } 200 \mathrm{mg} \text { QD x } 6 \\
\text { days, or } 100 \mathrm{mg} \text { BID } \\
\text { x } 5 \text { days) } \\
\text { - } \mathrm{C}_{\max }: 25.5-483.8 \\
\mathrm{nM} \\
\text { - } \mathrm{C}_{\operatorname{maxu}}: 0.05-0.97 \\
\mathrm{nM}\end{array}$ & $\begin{array}{ll}- & \text { AUCR: } 2.09- \\
& 2.53 \\
\text { - } & \mathrm{C}_{\max } \mathrm{R}: 1.78- \\
& 2.69 \\
- & \mathrm{CL}_{\mathrm{r}} \mathrm{R}: \mathrm{NS}\end{array}$ & See above & $\mathrm{g}$ \\
\hline
\end{tabular}




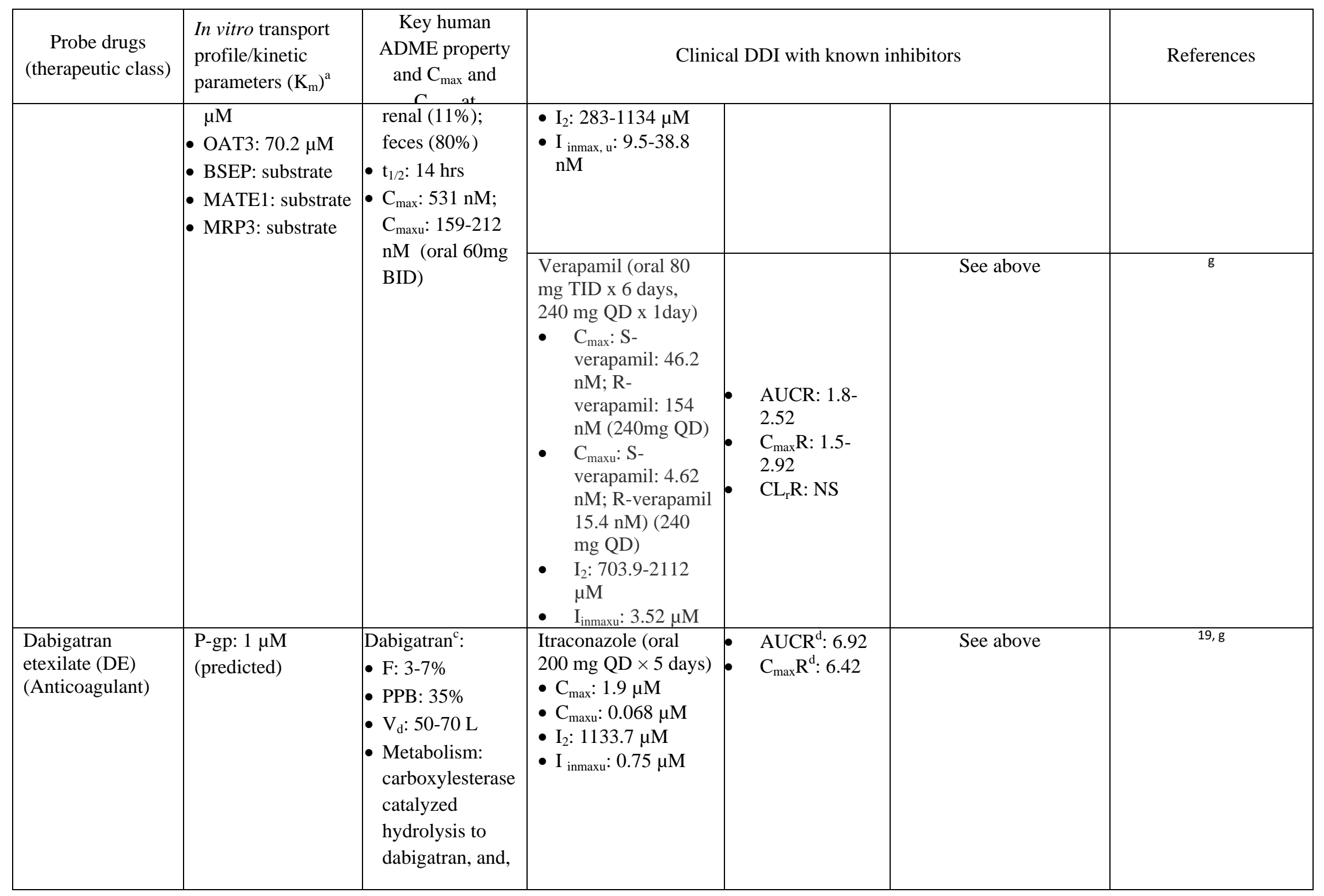




\begin{tabular}{|c|c|c|c|c|c|c|}
\hline \multirow[t]{2}{*}{$\begin{array}{c}\text { Probe drugs } \\
\text { (therapeutic class) }\end{array}$} & \multirow{2}{*}{$\begin{array}{l}\text { In vitro transport } \\
\text { profile/kinetic } \\
\text { parameters }\left(\mathrm{K}_{\mathrm{m}}\right)^{\mathrm{a}}\end{array}$} & \multirow[b]{2}{*}{$\begin{array}{l}\text { Key human } \\
\text { ADME property } \\
\text { and } \mathrm{C}_{\text {max }} \text { and } \\
r \text { at } \\
\text { then form acyl } \\
\text { glucuronides by } \\
\text { conjugation } \\
\text { - Elimination: } \\
\text { (after IV dose): } \\
\text { renal (85\%); } \\
\text { (after PO dose): } \\
\text { urine (7\%) and } \\
\text { feces }(86 \%) \\
\text { - } \mathrm{t}_{1 / 2}: 12-17 \mathrm{hrs} \\
\text { - } \mathrm{C}_{\max }: 174 \mathrm{nM} ; \\
\mathrm{C}_{\operatorname{maxu}}: 113 \mathrm{nM} \\
(100 \mathrm{mg} \text { DE oral } \\
\text { SD) } \\
\text { - } \mathrm{C}_{\max }: 341 \mathrm{nM} ; \\
\mathrm{C}_{\operatorname{maxu}}: 222 \mathrm{nM} \\
(200 \mathrm{mg} \text { DE oral } \\
\text { SD) }\end{array}$} & \multicolumn{3}{|c|}{ Clinical DDI with known inhibitors } & \multirow{2}{*}{$\begin{array}{c}\text { References } \\
99\end{array}$} \\
\hline & & & $\begin{array}{l}\text { Verapamil (oral } 120 \\
\text { mg IR SD or oral } 240 \\
\text { mg ER SD) } \\
\text { - } \mathrm{C}_{\max }: 205.5-275 \\
\mathrm{nM} \\
\text { - } \mathrm{C}_{\max }: 20.5-27.5 \\
\mathrm{nM} \\
\text { - } \mathrm{I}_{2}: 1056-2112 \mu \mathrm{M}\end{array}$ & $\begin{array}{ll}\text { - } & \text { AUCR: 1.71- } \\
& 2.43 \\
- & \mathrm{C}_{\max } \mathrm{R}: 1.91- \\
& 2.79\end{array}$ & See above & \\
\hline \multicolumn{7}{|l|}{ BCRP } \\
\hline $\begin{array}{l}\text { Rosuvastatin } \\
\text { (HMG Co-A } \\
\text { reductase } \\
\text { inhibitor) }\end{array}$ & See above & See above & $\begin{array}{l}\text { Fostamatinib }^{\mathrm{e}} \text { (oral } \\
100 \mathrm{mg} \mathrm{BID}, \mathrm{x} 9 \\
\text { days) } \\
\text { - } \mathrm{C}_{\max }(\text { active moiety } \\
\mathrm{R} 406): 1.6 \mu \mathrm{M} \\
\text { - } \mathrm{C}_{\max }(\text { active } \\
\text { moiety } \mathrm{R} 406) \text { : } \\
0.029 \mu \mathrm{M} \\
\text { - } \mathrm{I}_{2} \text { (fostamatinib): } \\
691 \mu \mathrm{M} \\
\text { - } \mathrm{I}_{\text {inmaxu }}(\mathrm{R} 406):\end{array}$ & $\begin{array}{ll}\text { - } & \text { AUCR: } 1.96 \\
\text { - } & \mathrm{C}_{\max } \mathrm{R}: 1.88\end{array}$ & $\begin{array}{l}\text { Fostamatinib: } \\
\text { - BCRP: } 0.05 \mu \mathrm{M} \\
\text { - P-gp: } 3.2 \mu \mathrm{M} \\
\text { active moiety R406: } \\
\text { - BCRP: } 0.031 \mu \mathrm{M} \\
\text { - OATP1B1: > } 10 \mu \mathrm{M} \\
\text { - OAT3: NI }\end{array}$ & $\mathrm{g}$ \\
\hline
\end{tabular}




\begin{tabular}{|c|c|c|c|c|c|c|}
\hline \multirow[t]{3}{*}{$\begin{array}{c}\text { Probe drugs } \\
\text { (therapeutic class) }\end{array}$} & $\begin{array}{l}\text { In vitro transport } \\
\text { profile/kinetic }\end{array}$ & $\begin{array}{c}\text { Key human } \\
\text { ADME property } \\
\text { and } C_{m a x} \text { and }\end{array}$ & \multicolumn{3}{|c|}{ Clinical DDI with known inhibitors } & \multirow[t]{2}{*}{ References } \\
\hline & & & $0.289 \mu \mathrm{M}$ & & & \\
\hline & & & $\begin{array}{l}\text { Rifampin (oral } \\
\text { 600mg SD IV and } \\
\text { PO) } \\
\text { PO: } \\
\text { - } \mathrm{C}_{\max }: 12.2 \mu \mathrm{M} \\
\text { - } \mathrm{C}_{\max }: 3.04 \mu \mathrm{M} \\
\text { - } \mathrm{I}_{2}: 2916 \mu \mathrm{M} \\
\text { - } \mathrm{I}_{\text {inmaxu }}: 15.2 \mu \mathrm{M} \\
\text { IV: } \\
\text { - } \mathrm{C}_{\max }: 24.3 \mu \mathrm{M} \\
\text { - } \mathrm{C}_{\max }: 6.08 \mu \mathrm{M}\end{array}$ & $\begin{array}{l}\text { PO Rifampin: } \\
\text { - AUCR: } 4.37 \\
\text { - } \mathrm{C}_{\max } \mathrm{R}: 9.93 \\
\text { IV Rifampin: } \\
\text { - AUCR: } 3.30 \\
\text { - CmaxR:5.51 }\end{array}$ & See above & 22 \\
\hline
\end{tabular}




\begin{tabular}{|c|c|c|c|c|c|c|}
\hline $\begin{array}{c}\text { Probe drugs } \\
\text { (therapeutic class) }\end{array}$ & $\begin{array}{l}\text { In vitro transport } \\
\text { profile/kinetic }\end{array}$ & $\begin{array}{c}\text { Key human } \\
\text { ADME property } \\
\text { and } \mathrm{C}_{\max } \text { and }\end{array}$ & \multicolumn{3}{|c|}{ Clinical DDI with known inhibitors } & References \\
\hline $\begin{array}{l}\text { Sulfasalazine } \\
\text { (Salicylate- } \\
\text { sulfonamide) }\end{array}$ & $\begin{array}{ll}\text { - } & \text { BCRP: } 0.7 \mu \mathrm{M} \\
\text { - } & \text { OATP2B1: } \\
& 1.73 \mu \mathrm{M} \\
\text { - } & \text { MRP2: } \\
& \text { substrate } \\
\text { - } & \text { P-gp: substrate }\end{array}$ & $\begin{array}{l}\text { - F: } 3-12 \% \\
\text { PPB: >99.3\% } \\
\text { - } \mathrm{V}_{\mathrm{d}}: 0.11 \mathrm{~L} / \mathrm{kg} \\
\text { Metabolism: } \\
\text { metabolized by } \\
\text { intestinal } \\
\text { bacteria to 5- } \\
\text { aminosalicylic } \\
\text { acid (5-ASA) } \\
\text { and } \\
\text { sulfapyridine } \\
\text { (SP) in the } \\
\text { intestine, and in } \\
\text { liver to these } \\
\text { moieties by } \\
\text { some extent. } \\
\text { Elimination: } \\
\text { Absorbed SP } \\
\text { and 5-ASA and } \\
\text { their metabolites } \\
\text { are primarily } \\
\text { eliminated into } \\
\text { urine; CL } \mathrm{C}: 37 \% \\
\text { of CL. } \\
\text { - } \mathrm{t}_{1 / 2}: 7.6 \text { hrs } \\
\text { - } \mathrm{C}_{\text {max }}: 37.6-79 \\
\mu \mathrm{M} ; \mathrm{C}_{\operatorname{maxu}}: \\
0.26-0.55 \mu \mathrm{M} \\
(3-4 \mathrm{~g} \text { oral } \mathrm{SD} \text { ) }\end{array}$ & $\begin{array}{l}\text { Curcumin (oral } 2 \mathrm{~g} \text {, } \\
\mathrm{SD} \text { ) } \\
\mathrm{C}_{\text {avg: }}:<0.5 \mathrm{ng} / \mathrm{mL} \\
\text { (lower limit of } \\
\text { quantification) }\end{array}$ & 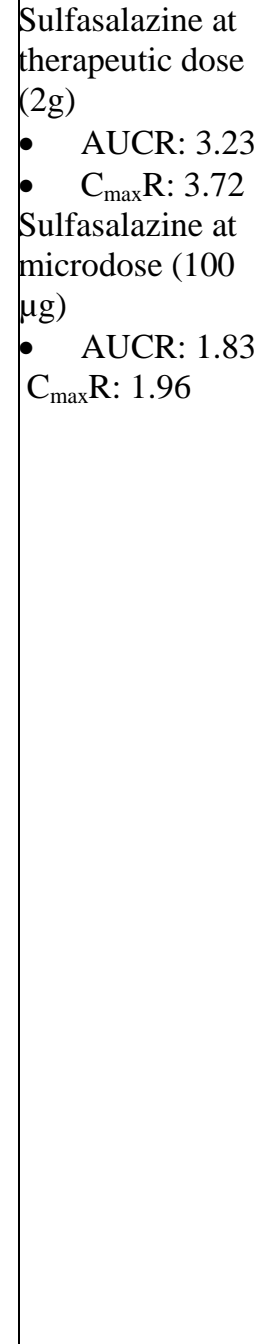 & $\begin{array}{l}\text { - BCRP: } 0.62-32 \mu \mathrm{M} \\
\text { - MRP1: } 16.1 \mu \mathrm{M} \\
\text { - OATP1B1: } 33.7 \mu \mathrm{M} \\
\text { - OATP1B3: } 3.81 \mu \mathrm{M} \\
\text { - P-gp: 5.8-50.5 } \mu \mathrm{M}\end{array}$ & 80 \\
\hline
\end{tabular}




\begin{tabular}{|c|c|c|c|c|c|c|}
\hline $\begin{array}{c}\text { Probe drugs } \\
\text { (therapeutic class) }\end{array}$ & $\begin{array}{l}\text { In vitro transport } \\
\text { profile/kinetic } \\
\text { parameters }\left(\mathrm{K}_{\mathrm{m}}\right)^{\mathrm{a}}\end{array}$ & $\begin{array}{c}\text { Key human } \\
\text { ADME property } \\
\text { and } \mathrm{C}_{\max } \text { and } \\
\mathrm{C}\end{array}$ & \multicolumn{3}{|c|}{ Clinical DDI with known inhibitors } & References \\
\hline \multicolumn{7}{|l|}{ OAT1/OAT3 } \\
\hline $\begin{array}{l}\text { Adefovir }{ }^{\mathrm{f}} \\
\text { (Antivirals) }\end{array}$ & $\begin{array}{ll}\text { - } & \text { OAT1: 11.4- } \\
& 30 \mu \mathrm{M} \\
\text { - } & \text { MRP4: } \\
& \text { substrate }\end{array}$ & $\begin{array}{ll}\text { - } & \text { F: } 59 \% . \\
\text { - } & \text { PPB: } \leq 4 \% \\
\mathrm{~V}_{\mathrm{dss}}: 352- \\
392 \mathrm{ml} / \mathrm{kg} \\
\text { - } \\
\text { Metabolism: } \\
\text { adefovir } \\
\text { dipivoxil is } \\
\text { rapidly } \\
\text { converted to } \\
\text { adefovir } \\
\text { Elimination: } \\
\text { renal (45\% } \\
\text { in } 24 \text { hrs as } \\
\text { adefovir); } \\
\text { active } \\
\text { secretion and } \\
\text { glomerular } \\
\text { filtration } \\
\mathrm{t}_{1 / 2}: 7.48 \text { hrs } \\
\mathrm{C}_{\text {max }}: 0.067 \\
\mu \mathrm{M} ; \mathrm{C}_{\operatorname{maxu}}: \\
0.065 \mu \mathrm{M} \\
\text { (10 mg } \\
\text { adefovir } \\
\text { dipivoxil } \\
\mathrm{QD})\end{array}$ & $\begin{array}{l}\text { Probenecid (oral, } \\
750 \mathrm{mg}, \mathrm{SD} \text { ) } \\
\text { - } \mathrm{C}_{\max }: 189 \mu \mathrm{M} \\
\text { - } \mathrm{C}_{\max , \mathrm{u}}: 18.9 \mu \mathrm{M}\end{array}$ & $\begin{array}{ll}- & \text { AUCR: } 2.09 \\
- & \text { GFR ratio: } \\
& 0.97 \\
\text { - } & \text { CL }_{\mathrm{r}} \mathrm{R}: 0.44 \\
& \\
\end{array}$ & $\begin{array}{l}\text { - OAT1: 3.6-27.4 } \mu \mathrm{M} \\
\text { - OAT3: 0.76-29.8 } \mu \mathrm{M} \\
\text { - MRP2: } 35.7-2300 \mu \mathrm{M} \\
\text { - MRP4: 8-77\% } \\
\text { inhibition at } 100 \mu \mathrm{M} \\
\text { - OAT2: 393-853 } \mu \mathrm{M} \\
\text { - OAT4: 15.5-134 } \mu \mathrm{M} \\
\text { - OATP1B1: } 39.8-740 \\
\mu \mathrm{M} \\
\text { - OATP1B3: } 130 \mu \mathrm{M} \\
\text { - URAT1: } 13.2-50 \mu \mathrm{M}\end{array}$ & $56, g$ \\
\hline
\end{tabular}




\begin{tabular}{|c|c|c|c|c|c|c|}
\hline $\begin{array}{c}\text { Probe drugs } \\
\text { (therapeutic class) }\end{array}$ & $\begin{array}{l}\text { In vitro transport } \\
\text { profile/kinetic } \\
\text { parameters }\left(\mathrm{K}_{\mathrm{m}}\right)^{\mathrm{a}}\end{array}$ & $\begin{array}{c}\text { Key human } \\
\text { ADME property } \\
\text { and } C_{\max } \text { and }\end{array}$ & \multicolumn{3}{|c|}{ Clinical DDI with known inhibitors } & References \\
\hline $\begin{array}{l}\text { Furosemide } \\
\text { (Diuretics) }\end{array}$ & $\begin{array}{l}\text { - OAT1: } 38.9 \mu \mathrm{M} \\
\text { - OAT3: } 21.5 \mu \mathrm{M} \\
\text { - MRP4: substrate } \\
\text { - MRP2: substrate } \\
\text { - BCRP: substrate } \\
\text { - OATP1B1: } \\
\text { substrate } \\
\text { - OATP1B3: } \\
\text { substrate }\end{array}$ & $\begin{array}{l}\text { - F: } 71 \% \\
\text { - PPB: } 98.6 \% \\
\text { - } \mathrm{V}_{\mathrm{d}}: 0.13 \mathrm{~L} / \mathrm{kg} \\
\text { - Metabolism:glu } \\
\text { curonidation, } \\
12 \% \text { of oral } \\
\text { dose } \\
\text { - Elimination: } \\
\text { renal }(65 \%) \\
\text { - } \mathrm{t}_{1 / 2}: 1.3 \mathrm{hrs} \\
\text { - } \mathrm{C}_{\max }: 5.14 \mu \mathrm{M} ; \\
\mathrm{C}_{\operatorname{maxu}}: 0.07 \mu \mathrm{M} \\
(40 \mathrm{mg} \text { oral } \mathrm{SD})\end{array}$ & $\begin{array}{l}\text { Probenecid (oral, 1g, } \\
\text { SD) } \\
\text { - } \mathrm{C}_{\max }: 243.9 \mu \mathrm{M} \\
\text { - } \mathrm{C}_{\operatorname{maxu}}: 24.4 \mu \mathrm{M}\end{array}$ & $\begin{array}{ll}\text { - } & \text { AUCR: } 2.68 \\
\text { - } & \mathrm{CL}_{\mathrm{nr}} \mathrm{R}: 0.41 \\
& \mathrm{CL}_{\mathrm{r}} \mathrm{R}: 0.34\end{array}$ & See above & $17, \mathrm{~g}$ \\
\hline $\begin{array}{l}\text { Benzylpenicillin } \\
\text { (Penicillin G) } \\
\text { (antibiotics) }\end{array}$ & $\begin{array}{l}\text { - OAT3: 13.9-66 } \\
\mu \mathrm{M} \\
\text { - OAT1: } 884 \mu \mathrm{M} \text {, } \\
\text { or not a substrate } \\
\text { - OATP1B1: } \\
\text { substrate } \\
\text { - OATP1B3: } \\
\text { substrate } \\
\text { - }\end{array}$ & $\begin{array}{l}\text { - F\%: } 15-30 \% \\
\text { (fasting) } \\
\text { - PPB: } 45-68 \% \\
\text { - } \mathrm{V}_{\mathrm{d}}: 0.53-0.67 \\
\mathrm{~L} / \mathrm{kg} \\
\text { - Metabolism: 16- } \\
30 \% \\
\text { intramuscular } \\
\text { dose is } \\
\text { metabolized to } \\
\text { penicilloic acid } \\
\text { - Elimination: } \\
\text { renal } \\
\text { - } \mathrm{t}_{1 / 2}: 0.4-0.6 \mathrm{hr} \\
\text { - } \mathrm{C}_{\max } \text { and } \mathrm{C}_{\operatorname{maxu}}, \\
\mathrm{NR}\end{array}$ & $\begin{array}{l}\text { Probenecid (oral, } \\
1500 \mathrm{mg}, \mathrm{SD}) \\
\\
\text { - } \mathrm{C}_{\max }: 475 \mu \mathrm{M} \\
\text { - } \mathrm{C}_{\operatorname{maxu}}: 47.5 \mu \mathrm{M}\end{array}$ & $\begin{array}{ll}\text { - } & \text { AUCR: } 3.27 \\
\text { - } & \text { CL } L_{\mathrm{r}} \mathrm{R}: 0.22\end{array}$ & See Above & $56, \mathrm{~g}$ \\
\hline
\end{tabular}




\begin{tabular}{|c|c|c|c|c|c|c|}
\hline $\begin{array}{c}\text { Probe drugs } \\
\text { (therapeutic class) }\end{array}$ & $\begin{array}{l}\text { In vitro transport } \\
\text { profile/kinetic }\end{array}$ & $\begin{array}{c}\text { Key human } \\
\text { ADME property } \\
\text { and } \mathrm{C}_{\max } \text { and }\end{array}$ & \multicolumn{3}{|c|}{ Clinical DDI with known inhibitors } & \multirow[t]{2}{*}{ References } \\
\hline \multicolumn{6}{|l|}{ OCT2/MATE1/2K } & \\
\hline \multirow[t]{3}{*}{$\begin{array}{l}\text { Metformin } \\
\text { (biguanide, } \\
\text { glucose lowering } \\
\text { agent) }\end{array}$} & \multirow{3}{*}{$\begin{array}{l}\text { - OCT2: 235-3356 } \\
\mu \mathrm{M} \\
\text { - OCT1: 83.6-6360 } \\
\mu \mathrm{M} \\
\text { - MATE1: } 94.7- \\
\text { 4565 } \mu \mathrm{M} \\
\text { - MATE2K: 473- } \\
\\
2986 \mu \mathrm{M} \\
\text { - } \\
\text { OCT3: } 1020-3810 \\
\mu \mathrm{M} \\
\text { - } \mathrm{PMAT:} 1320 \mu \mathrm{M}\end{array}$} & \multirow{3}{*}{$\begin{array}{l}\cdot \mathrm{F}: 52 \% \\
\cdot \text { PPB: negligible } \\
\cdot \mathrm{V}_{\mathrm{d}}: 1.12 \mathrm{~L} / \mathrm{kg} \\
\cdot \text { Metabolism: } \\
\text { negligible } \\
\text { - Elimination: } \\
\text { renal }(\sim 90 \% \text { of } \\
\text { the absorbed } \\
\text { drug within the } \\
\text { first } 24 \mathrm{hrs}) \\
\cdot{ }^{-}{ }_{1 / 2}: 1.74 \mathrm{hrs} \\
\cdot \mathrm{C}_{\max }: 9.7 \mu \mathrm{M} ; \\
\mathrm{C}_{\max }: 9.7 \mu \mathrm{M} \\
(0.5 \mathrm{~g} \text { oral } \mathrm{SD})\end{array}$} & $\begin{array}{l}\text { Cimetidine (oral, } \\
400 \mathrm{mg}, \text { bid) } \\
\text { - } \mathrm{C}_{\max }: 9.35 \mu \mathrm{M} \\
\text { - } \mathrm{C}_{\operatorname{maxu}}: 7.58 \mu \mathrm{M}\end{array}$ & $\begin{array}{ll}\text { - } & \text { AUCR: 1.46- } \\
& 1.54 \\
\text { CL } & \\
& 0.72\end{array}$ & $\begin{array}{l}\text { - OCT2: 2.51-1650 } \mu \mathrm{M} \\
\text { - MATE1: 0.093-16.3 } \\
\mu \mathrm{M} \\
\text { - MATE2K: 2.1-46.6 } \\
\mu \mathrm{M} \\
\text { - OCT1: } 1.4-1010 \mu \mathrm{M} \\
\text { - OCT3: } 9.8-111 \mu \mathrm{M} \\
\text { - OAT3: } 0.07-215 \mu \mathrm{M} \\
\text { - OAT2: } 22-102.3 \mu \mathrm{M}\end{array}$ & $\mathrm{g}$ \\
\hline & & & $\begin{array}{l}\text { Pyrimethamine (oral, } \\
\text { 50mg, SD) } \\
\text { - } \mathrm{C}_{\max }: 2.29 \mu \mathrm{M} \\
\text { - } \mathrm{C}_{\operatorname{maxu}}: 0.30 \mu \mathrm{M}\end{array}$ & $\begin{array}{ll}\text { - } & \text { AUCR: 1.35- } \\
& 2.68 \\
\text { - } L_{\mathrm{r}} \mathrm{R}: 0.28- & \\
& 0.65\end{array}$ & $\begin{array}{l}\text { - MATE1: 0.04-0.92 } \mu \mathrm{M} \\
\text { - MATE2K: 0.046-1.5 } \\
\mu \mathrm{M} \\
\text { - OCT2: } 0.93-160 \mu \mathrm{M} \\
\text { - OCT1: } 1.8-8.5 \mu \mathrm{M} \\
\text { - OAT3: } 32 \mu \mathrm{M} \\
\text { - P-gp: } 37 \mu \mathrm{M}\end{array}$ & 65,66 \\
\hline & & & $\begin{array}{l}\text { Dolutegravir (oral, } \\
\text { 50mg QD and BID) } \\
\text { - } \mathrm{C}_{\max }: 9.08-16.2 \mu \mathrm{M} \\
\text { - } \mathrm{C}_{\operatorname{maxu}}: 0.1-0.18 \mu \mathrm{M}\end{array}$ & $\begin{array}{l}\text { AUCR: 1.79- } \\
2.45 \\
\text { - }\end{array}$ & $\begin{array}{l}\text { - OCT2: 0.066-8.25 } \mu \mathrm{M} \\
\text { - MATE1: 4.67-6.34 } \mu \mathrm{M} \\
\text { - MATE2K: 9.3-49.3 } \\
\\
\mu \mathrm{M} ;\end{array}$ & $\mathrm{g}$ \\
\hline
\end{tabular}


ADME, Absorption, distribution, metabolism, and excretion; AUC, area under the concentration-time curve; AUCR, ratio of AUC; BCRP, breast cancer resistance protein; CYP, cytochrome $\mathrm{P} 450 ; \mathrm{C}_{\max }$, maximum concentration in plasma; $\mathrm{C}_{\max } \mathrm{R}$, ratio of $\mathrm{C}_{\max }$; $\mathrm{C}_{\mathrm{avg}}$, average plasma concentration; $\mathrm{CL}_{\mathrm{r}}$, renal clearance; $\mathrm{CL}_{\mathrm{r}} \mathrm{R}$, ratio of $\mathrm{CL}_{\mathrm{r}} ; \mathrm{CL}_{\mathrm{nr}} \mathrm{R}$, ratio of non-renal clearance; $\mathrm{CL} / \mathrm{F}$, apparent clearance after oral dose; DE, dabigatran etexilate; ER, extended released; $\mathrm{F}$, bioavailability; $\mathrm{IC}_{50}$, half maximal inhibitory concentration; IR, immediate released; $\mathrm{K}_{\mathrm{m}}$, Michaelis constant; $\mathrm{K}_{\mathrm{i}}$, inhibition rate constant; $\mathrm{MDR}$, multidrug resistance; MRP, multidrug resistance protein; MATE, multidrug and toxin extrusion protein; NTCP, sodium taurocholate co-transporting polypeptide; NA, not applicable; NI, not inhibited; NR, not reported; NS, not significant; OATP, organic anion transporting polypeptide; OAT, organic anion transporter ; OCT, organic cation transporter; P-gp, P-glycoprotein; PK, pharmacokinetics; PPB, plasma protein binding; $\mathrm{t}_{1 / 2}$, half-life; THTR, thiamine transporter; $\mathrm{V}_{\mathrm{d}}$, volume distribution; $\mathrm{V}_{\mathrm{dss}}$, volume distribution at the steady state.

$\mathrm{I}_{2}$ is gut concentration and calculated as dose $/ 250 \mathrm{~mL}$ and $\mathrm{I}_{\text {inmaxu }}$ is unbound maximal inlet concentration and is calculated as

$\mathrm{f}_{\mathrm{u}, \mathrm{p}} *(\operatorname{Imax}+(\mathrm{FaFg} \times \mathrm{ka} \times$ Dose $)) / \mathrm{Qh} / \mathrm{RB}$ where $\mathrm{f}_{\mathrm{u}, \mathrm{p}}$ is unbound fraction in plasma, Fa is the fraction absorbed, Fg is the intestinal availability, ka is the absorption rate constant., $\mathrm{Qh}$ is the hepatic blood flow rate and $\mathrm{RB}$ is the blood-to-plasma concentration ratio.

a: Data are obtained from the University of Washington DDI database (https://www.druginteractioninfo.org).

${ }^{\mathrm{b}}$ : PK parameters are obtained from the University of Washington DDI database (https://www.druginteractioninfo.org) unless specified in the references; other data of ADME properties are obtained from drug labels

c: Plasma exposure of dabigatran was measured

${ }^{\mathrm{d}}$ : DE was administered in microdose $(375 \mu \mathrm{g})$

e: Fostamatinib is a prodrug (R788) that is rapidly and completely metabolized by dephosphorylation in the enterocytes of the intestine to the active systemic metabolite R406.

f: Administered with adefovir dipivoxil, a diester prodrug of adefovir.

g: Refer to the University of Washington Drug Interaction and Transport Database (www.druginteractioninfo.org). 
Table 3: Examples of potential clinical endogenous biomarkers of OATP1B, OAT1, OAT3, OCT2/MATE1, 2K for DDI evaluation.

\begin{tabular}{|c|c|c|c|c|c|c|c|}
\hline \multirow[b]{2}{*}{ Endogenous probe } & \multirow[b]{2}{*}{$\begin{array}{l}\text { In vitro transport } \\
\text { kinetics/selectivity } \\
\left(\mathrm{K}_{\mathrm{m}}\right)\end{array}$} & \multirow[b]{2}{*}{$\begin{array}{l}\text { Formation and } \\
\text { elimination mechanisms }\end{array}$} & \multirow[b]{2}{*}{$\begin{array}{l}\text { Change in patients with } \\
\text { genetically altered } \\
\text { transporter function }\end{array}$} & \multicolumn{2}{|c|}{ Clinical DDI with known inhibitors } & \multirow[b]{2}{*}{ Reference } & \multirow[b]{2}{*}{ Comments } \\
\hline & & & & $\begin{array}{l}\text { Inhibitor (Dose } \\
\text { and } \\
\text { administration } \\
\text { route) }\end{array}$ & $\begin{array}{l}\text { PK Change } \\
\text { (inhibitor/control) }\end{array}$ & & \\
\hline \multicolumn{8}{|l|}{ OATP1B1/OATP1B3 } \\
\hline \multirow[t]{3}{*}{$\begin{array}{l}\text { Coproporphyrin I } \\
\text { (CPI) and CPIII }\end{array}$} & \multirow[t]{3}{*}{$\begin{array}{l}- \text { OATP1B1: } 0.13 \\
\text { (CPI) and } 0.22 \mu \mathrm{M} \\
\text { (CPIII) } \\
\text { - OATP1B3: } 3.95 \\
\text { (CPI) and } 1.55 \mu \mathrm{M} \\
\text { (CPIII) } \\
\text { MRP2: } 7.7 \mu \mathrm{M} \\
\text { (CPI) } \\
\text { MRP3: substrate } \\
\text { (CPI/III) }\end{array}$} & \multirow[t]{3}{*}{$\begin{array}{l}\text { - Formation: } \\
\text { metabolically stable } \\
\text { byproducts of heme } \\
\text { biosynthesis } \\
\text { - Elimination: biliary } \\
\text { and renal excretions }\end{array}$} & \multirow[t]{3}{*}{$\begin{array}{l}\text { - Rotor syndrome (deficient } \\
\text { in OATP1B): decreased } \\
\text { biliary excretion and } \\
\text { increased urinary } \\
\text { excretion } \\
\text { - Dubin-Johnson syndrome } \\
\text { (deficient in MRP2): } \\
\text { increased urinary } \\
\text { excretion }\end{array}$} & $\begin{array}{l}\text { Rifampin (oral } \\
300 \text { and } 600 \mathrm{mg} \\
\text { SD) }\end{array}$ & $\begin{array}{l}\text { Rifampin 300mg: } \\
\text { - CPI AUCR: } 3.0 \\
\\
\text { Rifampin } 600 \mathrm{mg}: \\
\text { - CPI AUCR: } \\
\text { 4.0-4.6, } \\
\text { - CPI C }{ }_{\max } \text { R: 5.4- } \\
\text { 6.4 } \\
\text { - CPIII AUCR: } \\
\text { 3.3-3.4 } \\
\text { - } \text { CPIII C }_{\max } \mathrm{R}: 3.3 \\
\end{array}$ & $38,40,41, \mathrm{~b}$ & $\begin{array}{l}- \text { Biliary } \\
\text { clearance of } \\
\text { CPI is estimated } \\
\text { to contribute } \geq \\
85 \% \text { CPI total } \\
\text { clearance }^{91}\end{array}$ \\
\hline & & & & $\begin{array}{l}\text { GDC-0810 } \\
\text { (oral } 600 \mathrm{mg} \\
\text { QD) }\end{array}$ & $\begin{array}{l}-\mathrm{CPI} \mathrm{C}_{3 \mathrm{hh}} \mathrm{R}: 1.56 \\
-\mathrm{CPIII} \mathrm{C}_{3 \mathrm{hr}} \mathrm{R}: \\
1.52\end{array}$ & 39 & $\begin{array}{l}\text { - GDC-0810 } \\
\text { increased } \\
\text { pravastatin } \\
\text { AUCR of } 1.4\end{array}$ \\
\hline & & & & $\begin{array}{l}\text { JNJ-A (oral } 600 \\
\text { mg BID for } 8 \\
\text { days) }\end{array}$ & 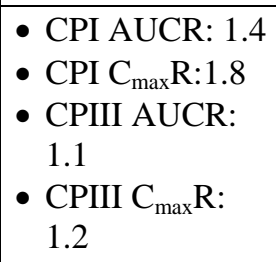 & 37 & $\begin{array}{l}\text { - JNJ-A } \\
\text { increased } \\
\text { pitavastatin } \\
\text { AUCR of } 1.5\end{array}$ \\
\hline $\begin{array}{l}\text { Glycochenodeoxycho } \\
\text { late-3-O-sulfate } \\
\text { (GCDCA-S) }\end{array}$ & $\begin{array}{l}\text { - OATP1B1: } 9.95 \\
\mu \mathrm{M} \\
\text { - OATP1B3: } 5.23\end{array}$ & $\begin{array}{l}\text { - Formation: bile acid } \\
\text { sulfation likely by } \\
\text { SULT2A1 }\end{array}$ & & $\begin{array}{l}\text { Rifampin (oral } \\
300 \text { and } 600 \mathrm{mg} \\
\text { SD) }\end{array}$ & $\begin{array}{l}\text { Rifampin 300mg: } \\
\text { - AUCR: } 4.3 \\
\text { - Rifampin } \\
\text { 600mg: }\end{array}$ & 34,41 & $\begin{array}{l}\text { - Metabolomics } \\
\text { and GWAS } \\
\text { studies }\end{array}$ \\
\hline
\end{tabular}




\begin{tabular}{|c|c|c|c|c|c|c|c|}
\hline \multirow[t]{2}{*}{ Endogenous probe } & \multirow{2}{*}{\begin{tabular}{|l|}
$\begin{array}{c}\text { In vitro transport } \\
\text { kinetics/selectivity }\end{array}$ \\
$\mu \mathrm{M}$ \\
- OAT3: $64.3 \mu \mathrm{M}$ \\
- NTCP: substrate
\end{tabular}} & \multirow{2}{*}{\begin{tabular}{|l|}
\multicolumn{1}{c}{ Formation and } \\
elimination mechanisms \\
- Elimination: biliary \\
excretion, renal \\
excretions, and \\
enterohepatic \\
recirculation
\end{tabular}} & \multirow[t]{2}{*}{$\begin{array}{l}\text { Change in patients with } \\
\text { genetically altered }\end{array}$} & \multicolumn{2}{|c|}{ Clinical DDI with known inhibitors } & \multirow[t]{2}{*}{ Reference } & \multirow[b]{2}{*}{\begin{tabular}{l}
\multicolumn{1}{c}{ Comments } \\
suggested that \\
GCDCA-S was \\
significantly \\
associated with \\
genetic variants \\
in OATP1B1
\end{tabular}} \\
\hline & & & & & • AUCR: 10-20.3 & & \\
\hline $\begin{array}{l}\text { Hexadecanedioate } \\
\text { (HDA) and } \\
\text { tetradecanedioate } \\
\text { (TDA) }\end{array}$ & 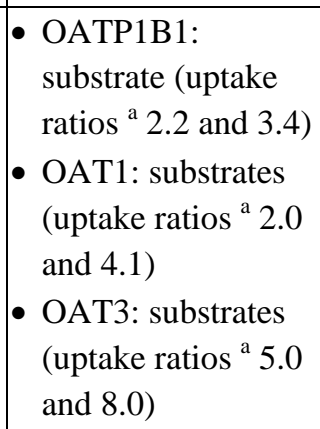 & $\begin{array}{l}\text { Formation: CYP4A11 } \\
\text { is involved in HDA and } \\
\text { TDA synthesis and/or } \\
\text { metabolism }\end{array}$ & $\begin{array}{l}\text { HDA and TDA are } \\
\text { significantly associated } \\
\text { with genetic variants in } \\
\text { OATP1B1 }\end{array}$ & $\begin{array}{l}\text { Rifampin(oral } \\
600 \text { mg SD) }\end{array}$ & $\begin{array}{l}\text { - AUCR: } 2.2 \text { and } \\
3.2\end{array}$ & 33,40 & \\
\hline $\begin{array}{l}\text { Unconjugated and } \\
\text { conjugated bilirubin } \\
\text { (UCB and CB) }\end{array}$ & $\begin{array}{l}- \text { OATP1B1: 0.008- } \\
0.16 \mu \mathrm{M}(\mathrm{UCB}) \\
\text { and } 0.1-0.28 \mu \mathrm{M} \\
\text { OATP1B3: } 0.039 \\
\text { and } 0.50 \mu \mathrm{M}\end{array}$ & $\begin{array}{l}\text { - Formation: bilirubin } \\
\text { glucuronidation by } \\
\text { UGT1A1 } \\
\text { - Elimination: biliary } \\
\text { excretion and } \\
\text { enterohepatic } \\
\text { recirculation }\end{array}$ & $\begin{array}{l}\text { Rotor syndrome (deficient } \\
\text { in OATP1B): decreased } \\
\text { biliary excretion } \\
\text { - SLCO1B } 1 * 15 / * 15 \\
\text { genotype (decreased } \\
\text { OATP1B1 activity): } \\
\text { increased plasma UCB } \\
\text { and CB levels }\end{array}$ & $\begin{array}{l}\text { Rifampin (oral } \\
300 \text { and } 600 \mathrm{mg} \\
\mathrm{SD})\end{array}$ & $\begin{array}{l}\text { Rifampin 300mg } \\
\text { - AUCR: } 1.6 \\
\text { (total bilirubin), } \\
2.3 \text { (CB) } \\
\\
\text { Rifampin } 600 \mathrm{mg} \\
\text { - AUCR: } 1.94 \\
\text { (UCB); } 0.85-3.5 \\
\text { (CB); } 1.32-2.09 \\
\text { (total bilirubin) }\end{array}$ & $19,29,40,41, \mathrm{~b}$ & \\
\hline \multicolumn{8}{|l|}{ OAT1/OAT3 } \\
\hline Taurine & - OAT1: $379 \mu \mathrm{M}$ & $\begin{array}{l}\text { - Formation: derived } \\
\text { from food or produced } \\
\text { from cysteine by } \\
\text { cysteine dioxygenase } \\
\text { and cysteine sulfonate } \\
\text { - Elimination: renal }\end{array}$ & & $\begin{array}{l}\text { Probenecid } \\
\text { (oral } 500,750, \\
\text { and } 1500 \mathrm{mg} \\
\text { SD) }\end{array}$ & $\begin{array}{l}\text { - AUCR: } 0.97 \text {, } \\
0.98 \text {, and } 1.02 \text {, } \\
\text { respectively } \\
\text { - } \mathrm{CL}_{\mathrm{r}} \mathrm{R}: 0.55 \text {, } \\
0.40 \text { and } 0.29 \text {, } \\
\text { respectively }\end{array}$ & 59 & $\begin{array}{l}- \text { Selective } \\
\text { substrate to } \\
\text { OAT1 over } \\
\text { OAT3 }\end{array}$ \\
\hline
\end{tabular}




\begin{tabular}{|c|c|c|c|c|c|c|c|}
\hline Endogenous probe & $\begin{array}{l}\text { In vitro transport } \\
\text { kinetics/selectivity }\end{array}$ & $\begin{array}{c}\text { Formation and } \\
\text { elimination mechanisms }\end{array}$ & $\begin{array}{l}\text { Change in patients with } \\
\text { genetically altered }\end{array}$ & \multicolumn{2}{|c|}{ Clinical DDI with known inhibitors } & \multirow[t]{2}{*}{ Reference } & \multirow[t]{2}{*}{ Comments } \\
\hline & & excretion & & & & & \\
\hline $\begin{array}{l}\text { 63-hydroxyl cortisol } \\
(6 \beta \mathrm{HC})\end{array}$ & $\begin{array}{l}\text { - OAT3: substrate } \\
\text { - MATE1: substrate }\end{array}$ & $\begin{array}{l}\text { - Formation: produced } \\
\text { from cortisol (an } \\
\text { endogenous substrate of } \\
\text { OAT3) by hepatic } \\
\text { CYP3A4 } \\
\text { - Elimination: renal } \\
\text { excretion }\end{array}$ & & $\begin{array}{l}\text { Probenecid } \\
\text { (oral } 750 \mathrm{mg} \\
\mathrm{SD} \text { ) }\end{array}$ & $\begin{array}{l}\text { - } \text { AUCR: } 1.57- \\
1.76 \\
\text { - } \mathrm{CL}_{\mathrm{r}} \mathrm{R}: 0.58-0.63\end{array}$ & $\mathrm{~b}$ & 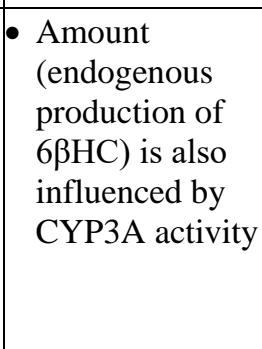 \\
\hline $\begin{array}{l}\text { Glycochenodeoxycho } \\
\text { late-3-O-sulfate } \\
\text { (GCDCA-S) }\end{array}$ & $\begin{array}{l}\text { - OATP1B1: } 9.95 \\
\mu \mathrm{M} \\
\text { - OATP1B3: } 5.23 \\
\mu \mathrm{M} \\
\text { - OAT3: } 64.3 \mu \mathrm{M} \\
\text { - NTCP: substrate }\end{array}$ & $\begin{array}{l}\text { - Formation: bile acid } \\
\text { sulfation likely by } \\
\text { SULT2A1 } \\
\text { - Elimination: biliary } \\
\text { excretion, renal } \\
\text { excretions, and } \\
\text { enterohepatic } \\
\text { recirculation }\end{array}$ & & $\begin{array}{l}\text { Probenecid } \\
\text { (oral 500, 750, } \\
\text { and } 1500 \mathrm{mg} \\
\text { SD) }\end{array}$ & $\begin{array}{l}\text { AUCR: } 1.06 . \\
1.00 \text {, and } 1.37 \text {, } \\
\text { respectively } \\
\text { - } \mathrm{CL}_{\mathrm{r}} \mathrm{R}: 0.38 \text {, } \\
0.21 \text { and } 0.11 \text {, } \\
\text { respectively }\end{array}$ & 59 & \\
\hline \multicolumn{8}{|l|}{ OCT2/MATEs } \\
\hline Creatinine & $\begin{array}{l}\text { - OCT2: 1.86-18.8 } \\
\text { mM } \\
\text { - MATE1: } 10.2 \mathrm{mM} \\
\text { - MATE2K: } 21.6 \\
\text { mM } \\
\text { - OAT2: 795-986 } \\
\mu \mathrm{M}\end{array}$ & $\begin{array}{l}\text { - Formation: produced } \\
\text { mainly by muscle } \\
\text { metabolism } \\
\text { - Elimination: primarily } \\
\text { filtered through the } \\
\text { kidney through the } \\
\text { glomeruli; } 10-40 \% \text { is }\end{array}$ & & $\begin{array}{l}\text { Cimetidine } \\
\text { (oral } 400 \mathrm{mg} \\
\text { QD) }\end{array}$ & $\begin{array}{l}\text { - AUCR: 1.13- } \\
1.26 \\
\text { - } \mathrm{CL}_{\mathrm{r}} \mathrm{R}: 0.80\end{array}$ & $66, \mathrm{~b}$ & \\
\hline
\end{tabular}




\begin{tabular}{|c|c|c|c|c|c|c|c|}
\hline \multirow[t]{2}{*}{ Endogenous probe } & \multirow[t]{2}{*}{$\begin{array}{c}\text { In vitro transport } \\
\text { kinetics/selectivity }\end{array}$} & \multirow{2}{*}{$\begin{array}{c}\text { Formation and } \\
\text { elimination mechanisms } \\
\text { actively secreted }\end{array}$} & \multirow[t]{2}{*}{$\begin{array}{c}\text { Change in patients with } \\
\text { genetically altered }\end{array}$} & \multicolumn{2}{|c|}{ Clinical DDI with known inhibitors } & \multirow[t]{2}{*}{ Reference } & \multirow[t]{2}{*}{ Comments } \\
\hline & & & & & & & \\
\hline & & & & $\begin{array}{l}\text { Pyrimethamine } \\
\text { (oral 50-100 mg } \\
\text { SD) }\end{array}$ & $\begin{array}{l}\text { - AUCR: } 1.18- \\
1.26 \\
\text { - } \mathrm{CL}_{\mathrm{r}} \mathrm{R}: 0.73-0.75\end{array}$ & $66, \mathrm{~b}$ & \\
\hline & & & & $\begin{array}{l}\text { Dolutegravir } \\
\text { (oral } 50 \mathrm{mg} \text { QD } \\
\text { or BID for } 4 \\
\text { days) }\end{array}$ & $\begin{array}{l}\text { - AUCR: } 1.09- \\
1.17 \\
\text { - } \text { CL }_{\mathrm{r}} \mathrm{R}: 0.86-0.90\end{array}$ & $\mathrm{~b}$ & \\
\hline \multirow[t]{2}{*}{$\begin{array}{l}\text { N1- } \\
\text { methylnicotinamide } \\
\text { (NMN) }\end{array}$} & $\begin{array}{l}\text { - OCT2: } 318 \mu \mathrm{M} \\
\text { - MATE1: } 301 \mu \mathrm{M} \\
\text { - MATE2K: } 422 \mu \mathrm{M}\end{array}$ & $\begin{array}{l}\text { - Formation: a } \\
\text { nicotinamide metabolite } \\
\text { produced by } \mathrm{N}- \\
\text { methyltransferase } \\
\text { Elimination: renal } \\
\text { excretions and } \\
\text { metabolism }\end{array}$ & & $\begin{array}{l}\text { Pyrimethamine } \\
\text { (oral } 50 \mathrm{mg} \mathrm{SD} \text { ) }\end{array}$ & $\begin{array}{l}\text { - AUCR: } 0.84 \\
\text { - } \mathrm{CL}_{\mathrm{r}} \mathrm{R}: 0.30\end{array}$ & 69 & \\
\hline & & & & $\begin{array}{l}\text { Trimethoprim } \\
\text { (oral } 200 \mathrm{mg} \\
\text { BID for } 5 \text { days) }\end{array}$ & $\begin{array}{l}\text { - AUCR: } 1.00 \\
\text { - } \mathrm{CL}_{\mathrm{r}} \mathrm{R}: 0.73\end{array}$ & 70 & \\
\hline
\end{tabular}

AUCR, ratio of AUC; $\mathrm{CL}_{r} \mathrm{R}$, ratio of $\mathrm{CL}_{\mathrm{r}} ; \mathrm{BID}$, twice a day; $\mathrm{C}_{\max } \mathrm{R}$, ratio of $\mathrm{C}_{\max } ; \mathrm{K}_{\mathrm{m}}$, Michaelis constant; $\mathrm{QD}$, once a day; $\mathrm{SD}$, single dose.

a: Uptake ratio is calculated by dividing uptake activity measured in the transporter cells by that in control cells.

${ }^{\mathrm{b}}$ : Refer to the University of Washington Drug Interaction and Transport Database (www.druginteractioninfo.org). 


\section{Renal tubular} lumen

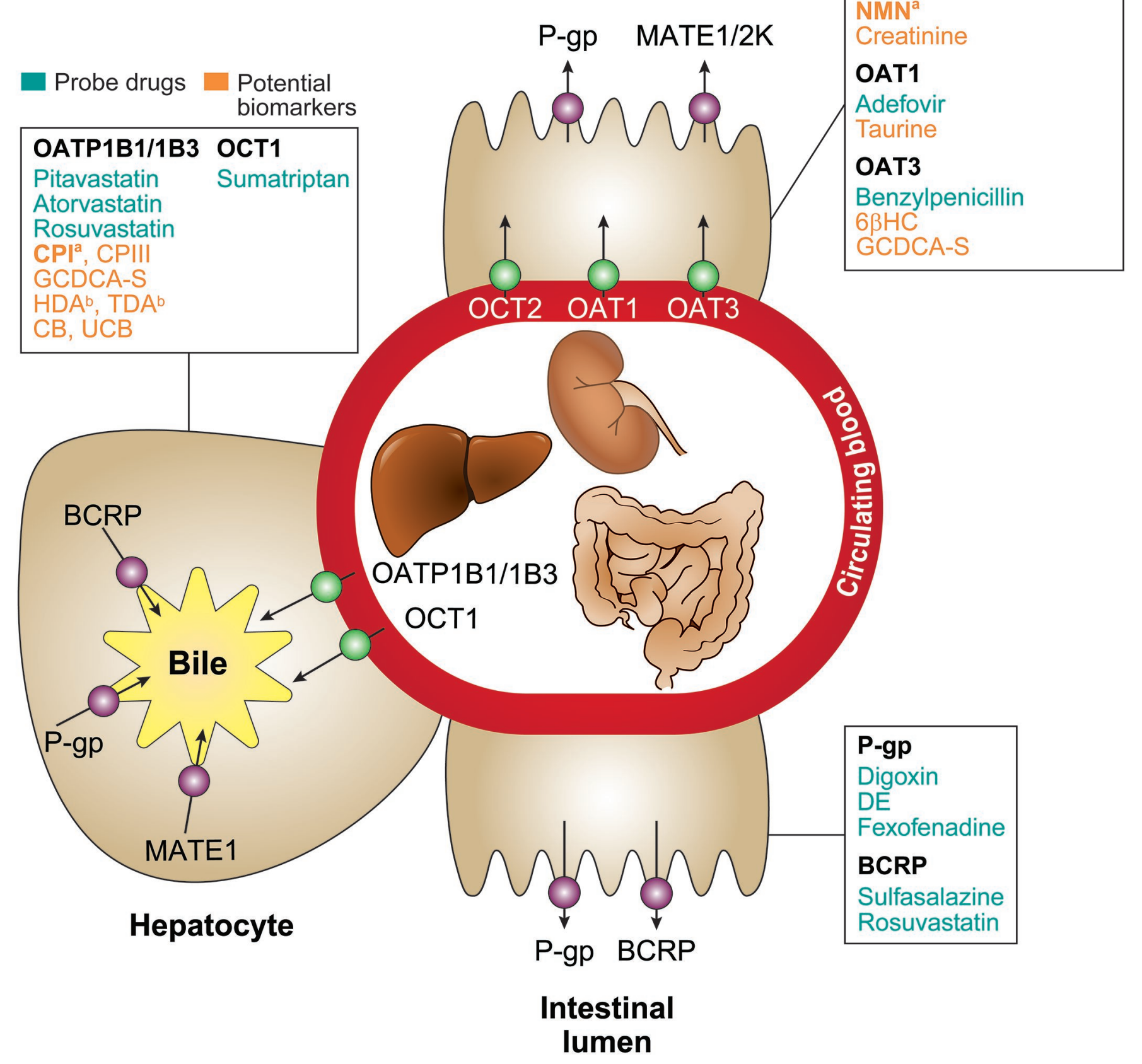




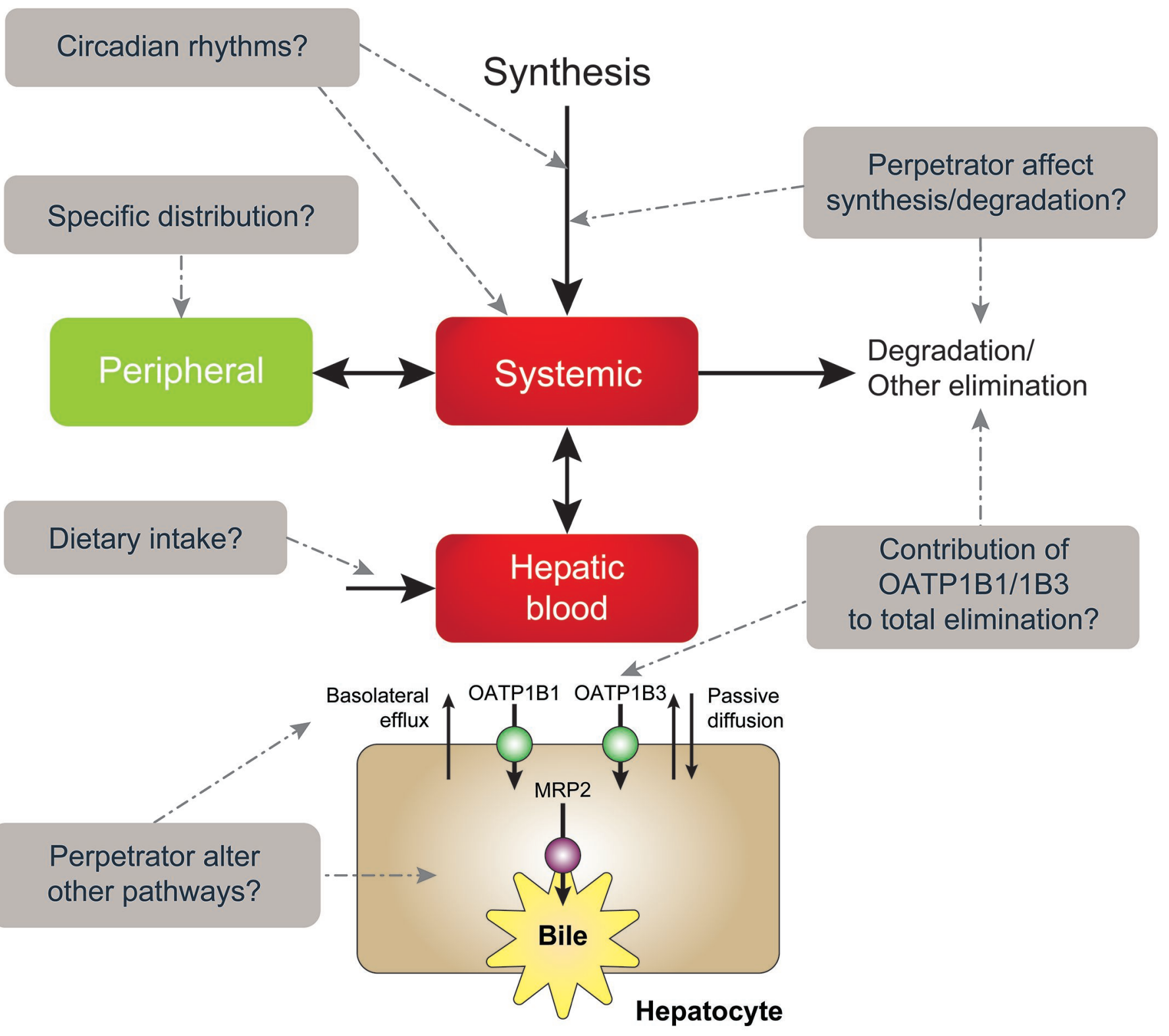


Recombinant in vitro systems

Rodent KO mode

\section{Quantitation Metabolomics or targeted assay}

Clinical disease model

Clinical DDI

\section{Identification}

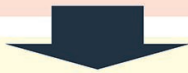

Identify candidate biomarkers with suitable sensitivity and/or specificity:

Change from baseline is robust with statistical significance and reproducible in two or more data types ${ }^{b}$

\section{Characterization}

\section{Clinical Selectivity towards a specific transporter:}

Compare the effects of model transport inhibitors and genetic polymorphism on the PK and elimination of candidate biomarkers

\section{In vitro specificity of candidate biomarkers for a transport process:}

Characterize the transport, formation, and elimination kinetics of the candidate biomarker and evaluate the effect of inhibitors on these processes
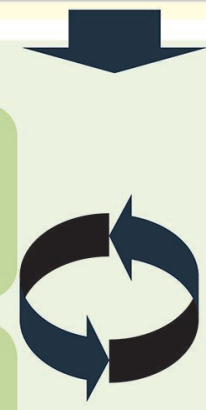

Clinical sensitivity:

Evaluate the magnitude of change from baseline in biological matrices at multiple time points in a sufficiently powered sample size to address physiological variability

\section{Mechanistic clinical deconstruction:}

Develop mechanistic PK models to optimize clinical utility. If needed, measure clinically candidate biomarker formation or elimination by administering labeled compound or parallel measurement of precursors

\section{Validation}

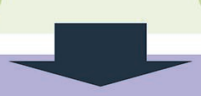

\section{Optimize analytical procedures and methods}

Design a dedicated prospective randomized crossover clinical DDI study with a known probe drug substrate, an inhibitor (multiplec), and quantitation of the selected candidate biomarker(s)

Use suitable dosing regimen and collect appropriate matrices over a suitable time frame pre- and post-dosing

Compare magnitude of PK changes relative to probe drug substrate(s)
Determine the optimal time frame and corresponding sensitivity based on PK changes of probe drug(s)
Compare PK changes across a panel of inhibitors to determine the selectivity of the candidate biomarker and the dynamic range

PK changes demonstrate a robust trend with increasing inhibitor concentrations that mirrors those observed with probe drug(s)

\section{Application}

Incorporate in clinical programs in "first-in-human" or in DDI investigations in combination with other probe drugs. Qualify the biomarker for the regulatory intended used ${ }^{d}$ 


\section{A. Pre-validated endogenous biomarkers and probe drugs}

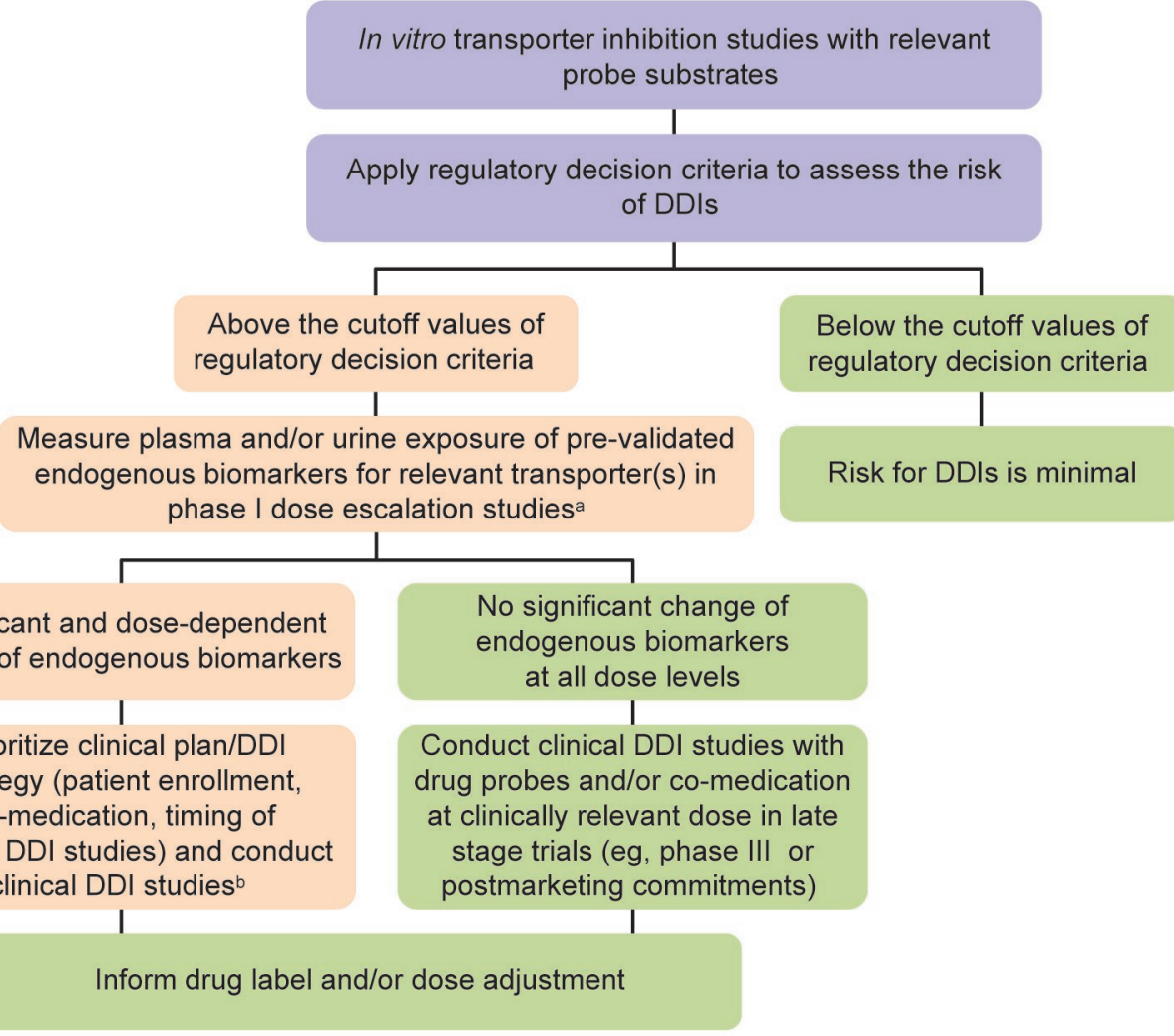

\section{B. Validated endogenous biomarkers and probe drugs}

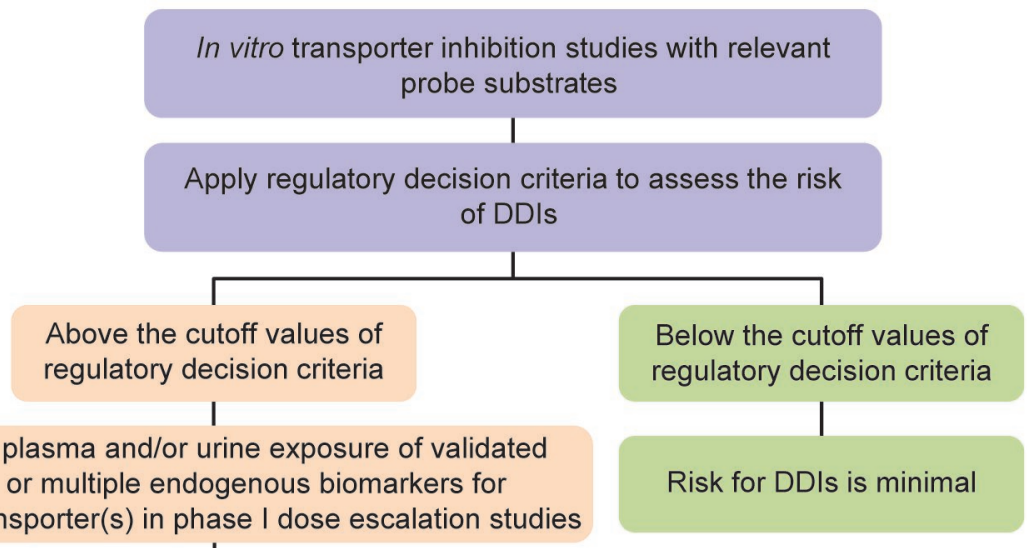

Significant and dose-dependent change of endogenous biomarkers

Measure plasma and/or urine exposure of validated single or multiple endogenous biomarkers for relevant transporter(s) in phase I dose escalation studies

Below the cutoff values of regulatory decision criteria

No significant change of endogenous biomarkers at all dose levels

Risk for DDls is minimal
Develop mechanistic PBPK models for endogenous biomarkers and quantitatively translate biomarker data to drug probes to predict the magnitude of DDls 